Argonne

\title{
Improvements of SAM Heat Transfer Models for Molten Salt-Cooled Pebble Bed Reactors
}

Nuclear Science and Engineering Division 


\section{About Argonne National Laboratory}

Argonne is a U.S. Department of Energy laboratory managed by UChicago Argonne, LLC under contract DE-AC02-06CH11357. The Laboratory's main facility is outside Chicago, at 9700 South Cass Avenue, Argonne, Illinois 60439. For information about Argonne and its pioneering science and technology programs, see www.anl.gov.

\section{DOCUMENT AVAILABILITY}

Online Access: U.S. Department of Energy (DOE) reports produced after 1991 and a growing number of pre-1991 documents are available free at OSTI.GOV (http://www.osti.gov/), a service of the US Dept. of Energy's Office of Scientific and Technical Information.

Reports not in digital format may be purchased by the public from the National Technical Information Service (NTIS):

U.S. Department of Commerce

National Technical Information Service

5301 Shawnee Rd

Alexandria, VA 22312

www.ntis.gov

Phone: (800) 553-NTIS (6847) or (703) 605-6000

Fax: (703) 605-6900

Email:orders@ntis.gov

Reports not in digital format are available to DOE and DOE contractors from the Office of Scientific and Technical Information (OSTI):

U.S. Department of Energy

Office of Scientific and Technical Information

P.O. Box 62

Oak Ridge, TN 37831-0062

www.osti.gov

Phone: (865) 576-8401

Fax: (865) 576-5728

Email: reports@osti.gov

\section{Disclaimer}

This report was prepared as an account of work sponsored by an agency of the United States Government. Neither the United States Government nor any agency thereof, nor UChicago Argonne, LLC, nor any of their employees or officers, makes any warranty, express or implied, or assumes any legal liability or responsibility for the accuracy, completeness, or usefulness of any information, apparatus, product, or process disclosed, or represents that its use would not infringe privately owned rights. Reference herein to any specific commercial product, process, or service by trade name, trademark, manufacturer, or otherwise, does not necessarily constitute or imply its endorsement, recommendation, or favoring by the United States Government or any agency thereof. The views and opinions of document authors expressed herein do not necessarily state or reflect those of the United States Government or any agency thereof, Argonne National Laboratory, or UChicago Argonne, LLC. 


\section{Improvements of SAM Heat Transfer Models for Molten Salt- Cooled Pebble Bed Reactors}

prepared by

Travis Mui, Ishak Johnson, Ling Zou, Rui Hu

Nuclear Science and Engineering Division, Argonne National Laboratory

June 2021 



\begin{abstract}
To support the development and utilization of the SAM code for molten salt-cooled pebble bed reactor safety analyses and licensing, selected improvements were made to the onedimensional system-level heat transfer modeling in SAM with the goal of better capturing heat transfer phenomena specific to these designs. In consideration of molten salt as a coolant, new models were introduced to capture the enhanced radiative heat transfer that must be considered at the higher working temperatures. Radiative heat transfer is handled not only between two structural surfaces, but also in combination between the surfaces and the molten salt fluid, which has a higher opacity and absorption of radiative heat as compared to water. Several examples of analytical verification of the new radiative heat transfer methods are included in this report. Additionally, convective heat transfer correlations were selected from literature and included in SAM to account for the enhanced heat transfer expected in pebble bed geometry flows. These correlations are verified and demonstrated in the present work with a reference FHR example.
\end{abstract}




\section{TABLE OF CONTENTS}

ABSTRACT

Table of Contents

List of Figures

List of Tables

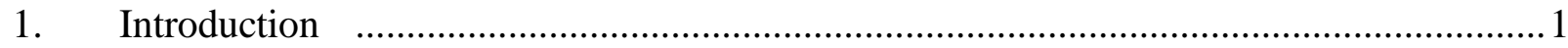

2. Improvements to Radiative Heat Transfer ..............................................................

2.1. Radiative heat transfer physics........................................................................

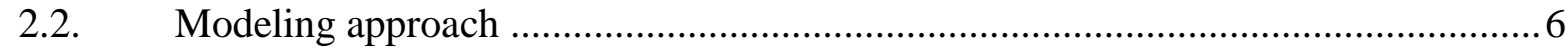

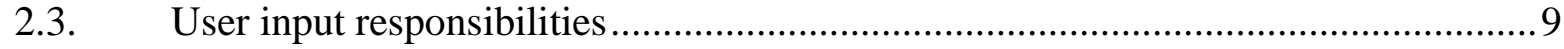

2.3.1. Surface-specific inputs .......................................................................... 10

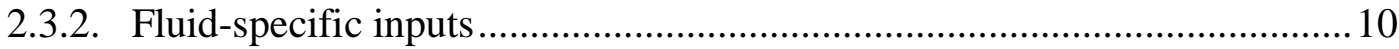

2.4. Testing of the radiative heat transfer component ................................................ 10

2.4.1. Concentric pipes energy balance testing for solid-to-solid coupling ...........11

2.4.2. Slab enclosure testing demonstrating convergence to analytical solution .. 12

2.4.3. Pipe flow demonstrating heating and cooling of walls by radiating fluid .. 14

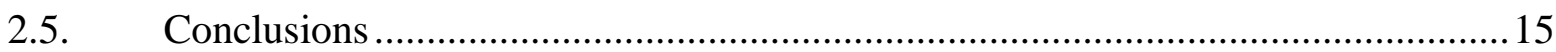

3. Closure Models Improvements for Molten Salt Heat Transfer........................................16

3.1. Selected convective heat transfer correlations ....................................................... 16

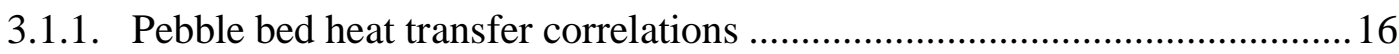

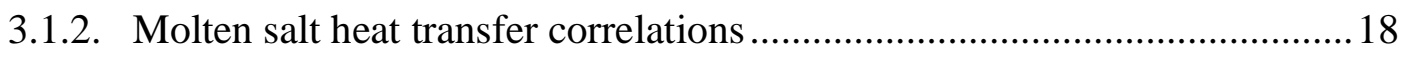

3.2. Verification and demonstration of selected correlations.....................................20

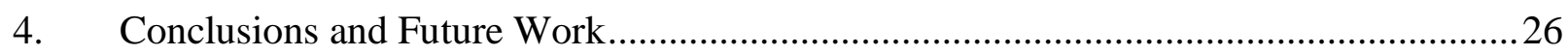

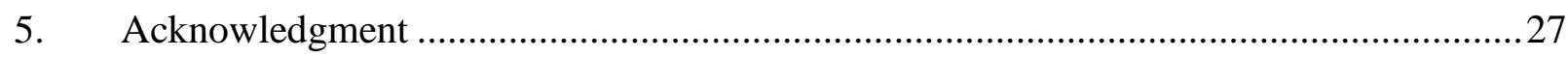

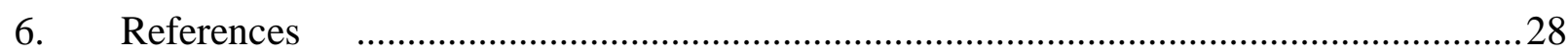




\section{LIST OF FIGURES}

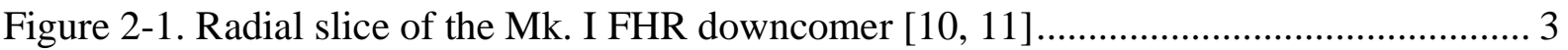

Figure 2-2. Radiative behavior of an interacting surface ............................................... 4

Figure 2-3. Radiative behavior of a participating medium along a line of sight. ................... 5

Figure 2-4. Two-body constraint infographic showing one constraint linking both bodies in the

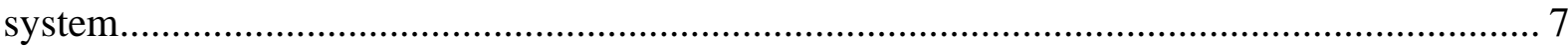

Figure 2-5. Three-body constraint infographic showing three constraints linking all bodies in

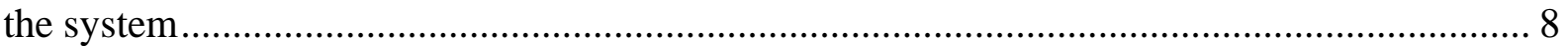

Figure 2-6. Geometry options for radiative enclosures built into the radiative heat transfer SAM

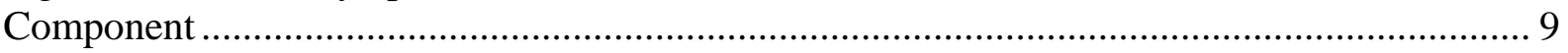

Figure 2-7. Concentric pipes with a radiation field between radiatively interacting surfaces . 11

Figure 2-8. Semi-infinite slab geometry with participating fluid flowing between parallel walls

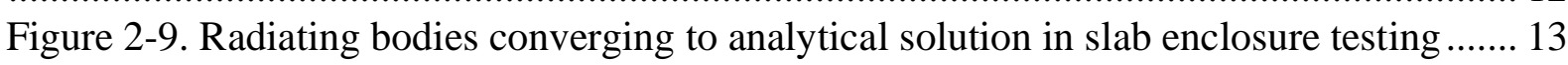

Figure 2-10. Wall temperature profile at time $=100 \mathrm{sec}$ in pipe heating and cooling testing 14

Figure 2-11. Axial temperature profiles demonstrating surface heating and cooling by the fluid in pipe heating and cooling testing. ...................................................................... 15

Figure 3-1. Comparison of Nusselt number as calculated by the KTA, Wakao, and Achenbach pebble bed flow correlations against the standard Dittus-Boelter value at equivalent Re...... 18 Figure 3-2. Comparison of Nusselt number as calculated by the Dittus-Boelter and Gnielinski correlations for a fluid with Prandtl number of 5 and 30, along with the minimum Nusselt value for laminar flow as determined by the Sellars correlation $(\mathrm{Nu}=4.36)$. ............................. 20 Figure 3-3. Horizontal pebble bed channel verification model with fluid domain (top) and averaged "stacked" spherical pebble coupled solid domain (bottom) shown with their simulated

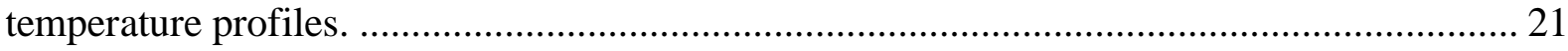

Figure 3-4. Pebble center temperature over the axial length of a horizontal pebble bed, comparing different correlations for pebble-fluid convective heat transfer.......................... 22 Figure 3-5. Radial temperature profile of an average pebble at the outlet of a horizontal pebble bed, comparing different correlations for pebble-fluid convective heat transfer................... 22

Figure 3-6. Dimensions of a generic PB-FHR reactor core [7]. ........................................ 23

Figure 3-7. Comparison of axial average axial temperatures (top) and the average pebble radial temperature profile (bottom) at the core midplane $(z=1.55 \mathrm{~m})$ with the KTA, Wakao, and

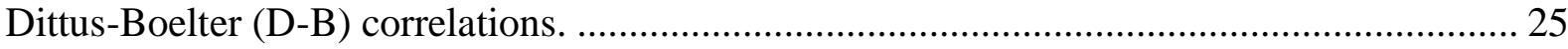




\section{LIST OF TABLES}

Table 2-1. Simulation capabilities for SAM radiative heat transfer modeling. 2 Table 2-2. Geometric parameters, initial conditions, and analytical temperature solutions for concentric pipes testing. 11

Table 2-3. Radiative parameters and analytical temperature solution for slab enclosure testing example. 12

Table 3-1. Horizontal pebble channel verification problem setup................................... 21 Table 3-2. Dimensions and operating parameters of the SAM generic reference FHR [7].... 24 


\section{Introduction}

System-level thermal hydraulics codes have been developed and used extensively for light water reactors (LWRs) design and licensing analyses. Due to increasing efforts to design safer, more economical reactors, there is a strong need for advanced simulation tools for system analysis of advanced reactors. In particular, the fluoride-salt-cooled high-temperature reactor (FHR) design is a promising candidate that leverages a TRISO pebble fuel form in combination with a low-pressure molten fluoride salt coolant. Molten fluoride salts have excellent chemical stability and a large capacity for transferring heat at high temperatures and retaining fission products. The ceramic fuel type can maintain structural integrity at extremely high temperatures, which is a significant advantage with regards to cooling capability under accident scenarios. Safety analysis for FHRs is vital to the development process, and thus there is a strong need to develop advanced tools to address simulation challenges unprecedented with regards to traditional LWRs analysis and, by extension, to existing safety analysis tools as well. These include fluid freezing and thawing, fluid as a participating medium in radiative heat transfer, pebble bed flow and heat transfer, and other phenomena specific to FHRs.

An advanced system analysis tool, SAM [1,2] is under development at Argonne National Laboratory for advanced non-LWR reactor safety analysis. It aims to provide fast-running, modest-fidelity, whole-plant transient analyses capabilities, which are essential for fast turnaround design scoping and engineering analyses of advanced reactor concepts. SAM takes advantage of advances in physical modeling, numerical methods, and software engineering to enhance its user experience and usability. It utilizes an object-oriented computational framework (MOOSE [3]), and its underlying meshing, finite-element library, linear, and nonlinear solvers, to leverage the modern advanced software environments and numerical methods.

SAM has been used to model PB-FHR designs, starting with simulations of the UC Berkeley Mark-1 design [4] that demonstrated the code's capability to model an FHR primary system. The collaboration with Kairos Power (KP) improved on various SAM capabilities and facilitated development of the related KP-SAM code [5] for KP's iterative design process and eventual licensing support of the KP-FHR design. Recent efforts have been made to provide a reference FHR model in SAM, including improvements to facilitate systems-level simulation in 1D and coupled multi-dimensional flow [6], considerations for unique component designs in FHRs such as the RCCS and enhanced heat exchangers, explicit pebble modeling under the porous medium framework, and improvements to $1 \mathrm{D}$ spherical heat conduction and pebble bed pressure drop prediction [7]. Earlier in FY21, an explicit model for pebble temperature calculations in the porous-medium framework has been developed and implemented in SAM for improved macroscopic (pebble-bed) and microscopic (pebble fuel) temperature predictions [8]. In this work, selected improvements were made to the one-dimensional flow modeling of heat transfer modeling in SAM specific to molten salt-cooled pebble bed reactors, which is further discussed in this report.

This report is organized as follows. Section 2 details the approach and improvements made to handling radiative heat transfer between solid-solid and solid-fluid coupled surfaces in SAM. Section 3 provides an overview of applicable empirical correlations for convective heat transfer in pebble bed flows and with molten salt, along with a verification and demonstration example. Finally, a short summary and follow-up work are discussed in Section 4. 


\section{Improvements to Radiative Heat Transfer}

Compared to traditional LWRs, FHRs are designed to operate in a higher temperature region to achieve higher thermal efficiency. For these types of reactors, radiative heat transfer becomes important. Currently, SAM only includes a simplified gap-conductance model to deal with surface-to-surface radiative heat transfer and lacks the ability to model radiative heat transfer (radHT) in more complicated scenarios, such as those where the fluid acts as a radiativelyparticipating body. Some advanced reactor coolants, particularly molten salt, further enhance the significance of radiative transfer due to their propensity to absorb and emit thermal radiation at a rate substantially higher than water. It is clear SAM requires the ability to simulate radiative heat transfer for complete safety analysis to be conducted.

System-level codes developed for LWRs include the ability to simulate radHT. However, these functions are computationally expensive [9]- to the point of being excluded whenever radHT can be assumed insignificant. Additionally, they rely heavily on LWR-specific correlations and were built to successfully simulate radHT in LWR-specific conditions. Radiative heat transfer simulation capabilities in SAM would ideally not mimic these particular attributes. SAM requires a flexible framework in which radHT simulation could be successfully carried out for numerous types of advanced reactor concepts and requires the ability to properly model radiative behavior without being computationally expensive.

Table 2-1. Simulation capabilities for SAM radiative heat transfer modeling.

\begin{tabular}{ccc}
\hline & \multicolumn{2}{r}{$\begin{array}{r}\text { Participating } \\
\text { Medium }\end{array}$} \\
\cline { 2 - 3 } Surfaces & No & Yes \\
\hline 1 & $\times$ & $\checkmark$ \\
2 & $\checkmark$ & $\checkmark$ \\
$3+$ & $\times$ & $\times$ \\
\hline
\end{tabular}

The extent of user-desired functionality for radiative heat transfer modeling, summarized in Table 2-1, was determined by reaching out to reactor design companies known by the author at the time to be utilizing SAM for molten-salt-cooled reactor analysis: Kairos Power and TerraPower. The general consensus was that participating media was strongly desired. However, the intended interaction between fluid and surfaces varied. One response requested "radiative heat transfer in cavities", listing a participating fluid known to be highly absorbing and emitting in the near infrared, implying a lumped-wall single-surface approximation would suffice. Another response was far more specific, listing the intended reactor regions and specific conditions for which radHT analysis was desired. For these conditions, two-surface enclosures were deemed necessary. No modeling scenarios involving three surfaces were discussed.

To exemplify the need for radHT modeling in an FHR, a multi-surface enclosure with a participating fluid was chosen from the Mark 1 (Mk. I) [10], a preconceptual reactor design from UC Berkeley, following some loss of forced flow. Figure 2-1 shows the downcomer region of the Mk. I. The inner surface of the downcomer, the core barrel, dissipates heat from the 
reactor core. For the chosen scenario, the outer surface of the enclosure, the reactor vessel, sits close to the bulk salt temperature $\left(600^{\circ} \mathrm{C}\right)$, making convective heat transfer miniscule. In this example, the inclusion of a multi-surface radHT enclosure with participating media is the only way to derive an accurate model of the component-level heat transfer between the core barrel and the reactor vessel. This example demonstrates a scenario for which SAM's radHT modeling capability must be developed to provide code users the tools necessary to properly simulate advanced reactor behavior. Radiative heat transfer modeling is not only necessary to simulate heat transfer for molten salt reactors and FHRs, but ultimately for performing accurate safety analysis for many advanced reactor designs.

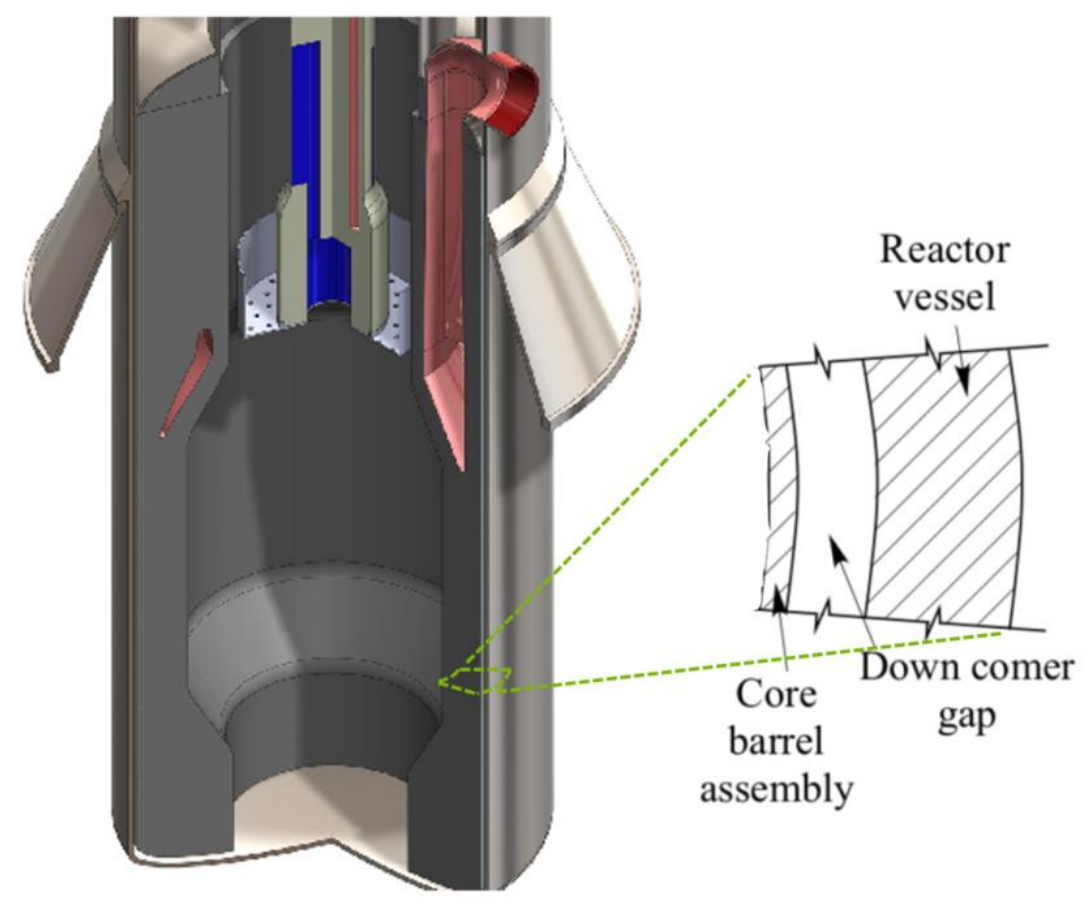

Figure 2-1. Radial slice of the Mk. I FHR downcomer [10, 11]

The ensuing sections detail the radHT modeling capabilities that were developed for, and implemented in, SAM. The current code capability allows for up to two solids and up to one fluid to interact via thermal radiation. This report will review the pertinent physics necessary to discuss the newly developed capabilities, the final formulation for radiative heat transfer implementation into SAM, and results from preliminary tests meant to demonstrate the code's new feature.

\subsection{Radiative heat transfer physics}

To better assist in describing the development of SAM's radiative heat transfer capabilities, it would be helpful to review some concepts of thermal radiation. The physics pertinent to the analysis carried out for radiative heat transfer implementation in SAM will be discussed in this section.

Radiative emissive power describes the energy being emitted by a radiating body. The amount of energy emitted scales with temperature to the fourth power of absolute temperature, as shown by Equation (1). 


$$
E=\varepsilon \sigma T^{4}
$$

This strong temperature dependence has serious implications for high temperature reactor systems, such as FHRs. Neglecting the change in emissivity, Equation (1) produces more than seven times the blackbody emissive power in an FHR operating at $700{ }^{\circ} \mathrm{C}$ than a current generation LWR operating at $320^{\circ} \mathrm{C}$. While LWR analysis typically does not consider radiative heat transfer less extraordinary temperature excursions, advanced reactor analysis might need to consider thermal radiation during normal operation.

Traditional radiative analysis involves describing the radiative behavior of interacting surfaces (see Figure 2-2). Surface characteristics can be described by emissivity $\varepsilon$, reflectivity $\rho$, and absorptivity $\alpha$. Emissivity describes the fraction of blackbody emission emitted by the surface. Incident radiation $G$ is either absorbed by the surface, $\alpha G$, or reflected away, $\rho G$. Emission, $\varepsilon \sigma T^{4}$ and reflected incidence are grouped together as radiosity, J. Increasing the number of interacting surfaces can quickly increase the complexity of surface radiation, as radiosity is now dependent on its own temperature and radiative properties, along with all other surfaces' temperatures and properties.

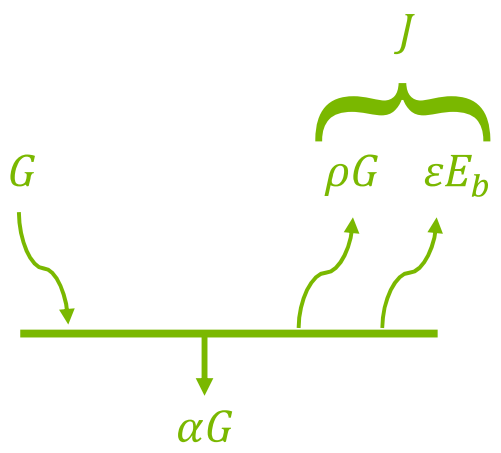

Figure 2-2. Radiative behavior of an interacting surface

Radiative behavior of fluids, which are called participating media in this regard, involve a bit more extravagant behavior. Incident radiation can pass through a fluid body, interacting with the fluid along the way. Shown as the dotted line in Figure 2-3, this absorption produces an exponential decay of incident radiation. The optical path seen by radiation is the path length $S$ multiplied by the absorption coefficient of the fluid $\kappa$. Additionally, this fluid body emits thermal radiation of its own, whose contributed effects are shown by the dashed line. The overall magnitude of fluid emission is dictated by fluid temperature, while the absorption coefficient controls attenuation and re-emission. Cumulative radiation behavior is made apparent by the solid line. Absorption and emission characteristics of fluids can vary substantially with impurity concentration, which further complicates radiative heat transfer analysis with participating media. 


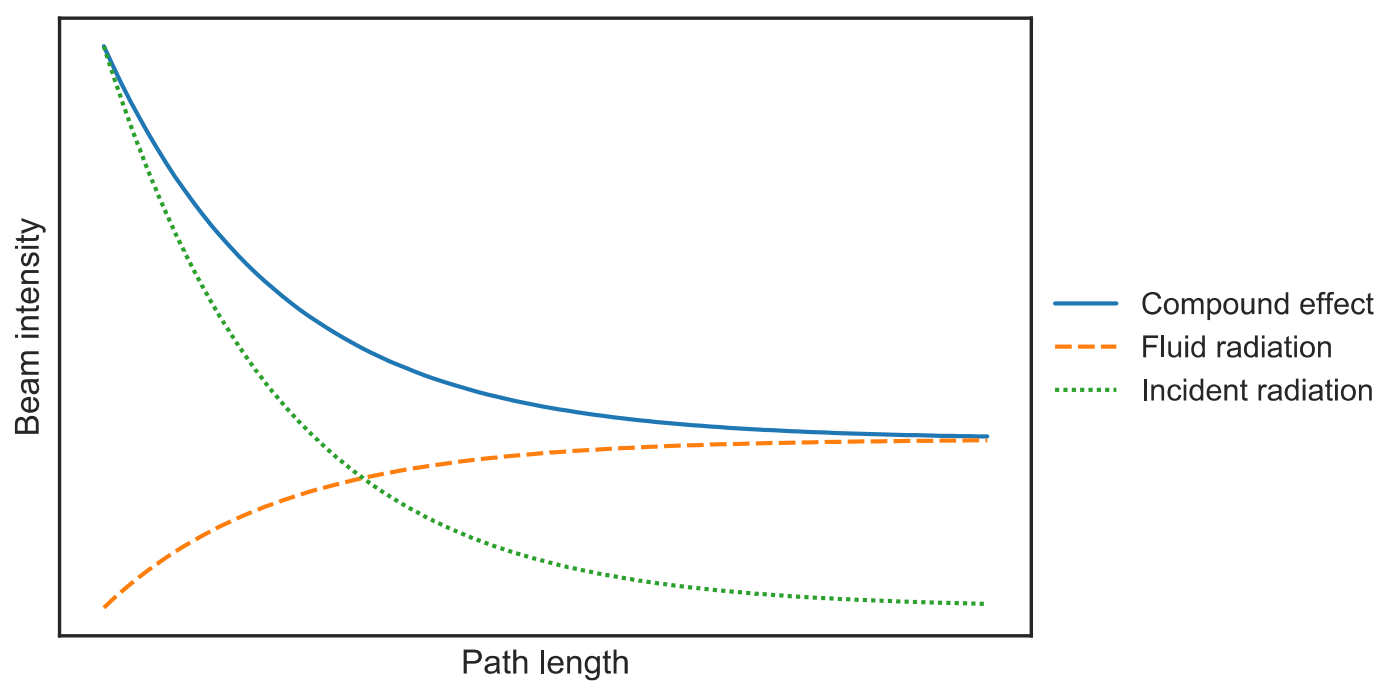

Figure 2-3. Radiative behavior of a participating medium along a line of sight.

The physics discussion up to this point has neglected a major detail of radiative transfer wavelength dependence of radiative properties. Emission, attenuation, re-emission, reflection, etc. all behave differently at different wavelengths. In halide salts, such as Flibe (primary coolant for FHRs), emissive power could receive a boost from the increase in absorption coefficient in the near infrared range [12]. Additionally, impurities will generate absorption bands in the salt, greatly enhancing solid-to-fluid heat transfer. Radiative properties such as surface emissivity and reflectivity vary along wavelength as well. To accurately describe radiative behavior of a system without solving an entirely separate set of equations for each wavelength band, spectral averaging of radiative properties is required, as shown by Equation (2). All surface and fluid radiative parameters must be spectrally-averaged in their applicable wavelength ranges to be used in ensuing analysis. While methods for spectral averaging are outside the scope of this paper, the readers are referred to Howell, et al. [13] and Modest [14]for further information.

$$
\bar{\psi}=\frac{\int_{\lambda_{1}}^{\lambda_{2}} \psi(\lambda) I_{\lambda} d \lambda}{\int_{\lambda_{1}}^{\lambda_{2}} I_{\lambda} d \lambda}
$$

Another common simplification for radiative heat transfer analysis is to make the so-called "grey" assumption. Surfaces that are grey assume that emissivity is equal to absorptivity. The analogous grey fluid assumption would equate emittance and absorptance. The physical basis for this assumption is that the same molecular/atomic rotational and vibrational energy states that are available for photon excitation (absorption) are also the energy states that are available for photon de-excitation (emission). This assumption generally holds quite well but breaks down when a radiating system contains large temperature discrepancies, as the spectra for incoming radiation can differ substantially from that which is being emitted. An interesting product of the grey assumption is that surface emissivity can be easily related to reflectivity (Equation (3)), as can fluid emittance to transmittance (Equation (4)). If properly treated, the 
grey assumption can greatly simplify radHT analysis while still maintaining a level of accuracy sufficient for safety analysis.

$$
\begin{gathered}
t=1-\alpha=\exp (-\kappa S) \\
\varepsilon=1-\rho
\end{gathered}
$$

\subsection{Modeling approach}

Solid-to-fluid radHT modeling was not included in SAM. Equation (5) shows the onedimensional fluid energy conservation equation as represented in the SAM Theory Manual [1] with the radiative term $\nabla q_{r}^{\prime \prime}$ bolded. However, this term is subsequently neglected in derivation due to restrictions stemming from SAM's computational framework. To maintain the radiative term in the fluid energy equation for SAM modeling, a modeling approach must be developed to not only capture the radiative contribution to heat transfer, but to also respect the modeling limitations at hand.

$$
\frac{\partial(\rho H)}{\partial t}+\frac{\partial(\rho u H)}{\partial z}=\nabla(k \nabla T)-\nabla \boldsymbol{q}_{r}^{\prime \prime}+q^{\prime \prime \prime}+\frac{D p}{D t}+\phi
$$

A literature review was conducted on the radHT implementation strategy in existing systemlevel thermal hydraulics codes, such as TRACE [9] and RELAP5 [15]. In these codes, the default treatment of thermal radiation relies on LWR-specific radiative parameter values and correlations dependent on flow regime to calculate solid-to-fluid radHT. These methods were implemented specifically for LWR analysis and should not be recycled and reused for SAM. These codes additionally implement a radiative simulation component based upon the net radiation method, which performs radiative heat transfer analysis in axial planes along the flow path for surfaces and a radiatively-absorbing fluid. Due to the computational intensity of this component, calculation is limited to scenarios in which some surface in the system is in postcritical heat flux. A complex component framework which leads to high computational intensity should be avoided. However, this methods' formulation does provide some valuable insight for how a more general and flexible radHT model could be developed for an advanced reactor system code. To develop an implementation approach suitable for SAM, the pertinent limiting factors, as well as user-desired functionality, should be heeded.

The bolded term in Equation (5) explicitly represents the divergence of the radiative flux, which inherently requires generating and solving for a radiative flux function - a function dependent on three-dimensional geometric and temperature information for all radiating bodies in the system. First and foremost, SAM is a system-level code that represents fluid flow primarily in a one-dimensional form. Therefore, the fluid heat source from radiation will not be able to be found from the divergence of a multi-dimensional radiative flux function. Additionally, this means no axial change in the radiative flux will be calculated either. In other words, no axial radHT. Thermal radiation will be isolated to separate axial planes along the flow path. In terms of mathematics, this formulation is equivalent to modeling radiative transfer within infinitely long geometries. Therefore, radHT modeling in SAM will be most accurate for enclosures whose lengths are much greater than their widths. The shorter and wider the radiating geometry becomes, the more inaccurate the results will be. However, this semi-infinite approximation is common for solid to fluid radiative transfer modeling, even for higher fidelity approaches [15]. 
Desires to keep SAM computationally inexpensive necessitates spectrally- and geometrically-averaged properties for radHT modeling. While spectral averaging cannot be done by SAM, the code can automatically derive view factors and optical paths based on a userdefined geometry to decrease burden on the user.

In addition to SAM-based limitations, there are restrictions specific to the computational framework SAM is built on, which limit radHT implementation approaches. Thermallyinteracting bodies are coupled together via a prebuilt, information access framework. By this approach, information sharing is restricted to two interacting entities - for instance temperature information for a convectively interacting solid-fluid pair can be accessed and used for calculating convective heat fluxes. The results of calculation can then be returned to these interacting bodies. However, net heat fluxes for radHT analysis require information from all participating bodies in the system, which can produce complications when utilizing a coupling framework inherently structured for two interacting bodies.

For two thermally radiating bodies, implementation is straightforward. Equation (6) shows the heat flux from some surface $\mathrm{k}$ as a function of the first surface's temperature, $f\left(T_{1}\right)$, summed with a function of the fluid body's temperature, $f\left(T_{f}\right)$. Both the surface and fluid will need to receive temperature information from themselves and the other radiating body to perform a full heat flux calculation. The required passing-of-information can be accomplished by a single instance of the "coupling framework", visualized by the set of arrows in Figure 2-4. Here, the blue, upper arrow shows the temperature information being accessed from Surface 1 and passed to the Fluid, while the green, lower arrow shows Fluid information being accessed and sent the other direction. In this system, each body can now construct a complete heat flux calculation using its own temperature information, which is inherently accessible, and the other's temperature information, which has been accessed and fed to it. Two bodies, 1 "coupling", no redundancies.

$$
q_{k}^{\prime \prime}=f\left(T_{1}\right)+f\left(T_{f}\right)
$$

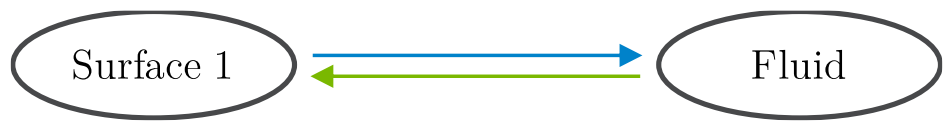

Figure 2-4. Two-body constraint infographic showing one constraint linking both bodies in the system

The complications arise when the radiative system is expanded to include three bodies, as all participants require information from themselves and two others. Equation (7) shows the required constituents for a complete heat flux calculation include functions of Surface 1's temperature, $f\left(T_{1}\right)$, Surface 2's temperature, $f\left(T_{2}\right)$, and the Fluid's temperature, $f\left(T_{f}\right)$. The adopted "coupling framework" (based on MOOSE Constraints system) cannot access all this information at once. The workaround is shown in Figure 2-5, where three individual "coupling frameworks" (each shown by a pair of arrows) are called to access and pass information such that heat flux calculations can be performed for all bodies in the system. Three redundancies arise, as information from each body is accessed by two separate "couplings". However, these redundancies are a necessary outcome of the coupling framework upon which thermal interaction in SAM is built. 


$$
q_{k}^{\prime \prime}=f\left(T_{1}\right)+f\left(T_{2}\right)+f\left(T_{f}\right)
$$

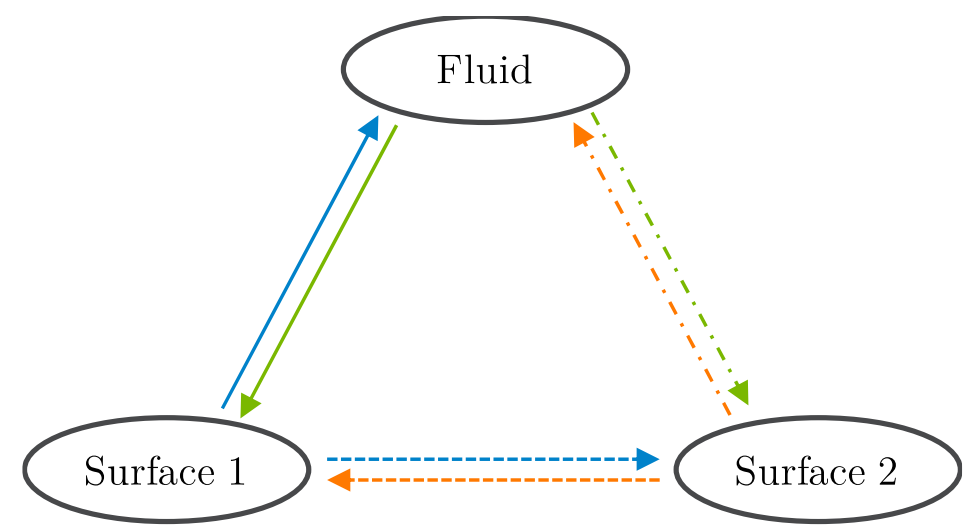

Figure 2-5. Three-body constraint infographic showing three constraints linking all bodies in the system

Taking all restrictions and limitations into consideration, a radHT modeling approach was developed to enable all user-desired modeling capabilities (Table 2-1). The general formulation is derived from the net radiation method. For the unmodified derivation of the net radiation equations, the reader is encouraged to peruse Sections 5.3.1 and 10.7 of Howell, Mengüç, and Siegel [13]. What the net radiation method does well is account for emission, reflection of that emission off multiple surfaces, and the absorption of the net radiation field at each surface. Using spectrally-averaged radiative parameters, easily manageable equations simultaneously solve for the total heat flux at each user-defined surface. The Kronecker delta $\delta$ is utilized to assist in visualizing the matrix formulation for this system of $N$ equations for each surface $k$.

$$
\delta_{k j}= \begin{cases}1 & k=j \\ 0 & k \neq j\end{cases}
$$

Here, the equations for the net radiation method are rederived with modifications to compensate for the lack of spectral variation in radiative properties. Namely, the grey assumption is not enforced. Therefore, spectrally-averaged radiative properties of an interacting body can be separated to represent different wavelength bands of incoming and outgoing radiation. Equation (9) and Equation (10) have been denoted the "Rad++" expression of the net radiation method, for brevity, and are the equations implemented in SAM.

$$
\begin{gathered}
\sum_{j=1}^{N}\left[\frac{\delta_{k j}}{1-\rho_{j}}-F_{k j} \bar{t}_{k j}\left(\frac{\rho_{j}}{1-\rho_{j}}\right)\right] q_{j}^{\prime \prime} \\
=\sum_{j=1}^{N}\left(\delta_{k j}-F_{k j} \bar{t}_{k j}\right)\left(\frac{\varepsilon_{j}}{1-\rho_{j}}\right) E_{b, j}-\sum_{j=1}^{N} F_{k j} \bar{\alpha}_{k j} E_{b, f} \\
q_{f}^{\prime \prime \prime}=\frac{1}{V_{f}} \sum_{k=1}^{N} q_{k}^{\prime \prime} A_{k}
\end{gathered}
$$

By allowing these user-specified parameters to be separated from the grey assumption, a more accurate solution to radHT can be found. However, the user should keep in mind that this 
is only a mathematical compensation for the true lack in spectral dependence of radiative parameters. If the user does not desire to bother with this convolution, true grey surfaces and true grey fluids can be modeled instead.

\subsection{User input responsibilities}

The user-inputs can be broken down into three categories: radHT geometry inputs, surfacespecific inputs, and fluid-specific inputs. Logic checks within the Rad++ component generally guide the user towards the necessary inputs by issuing warnings when parameters are amiss.
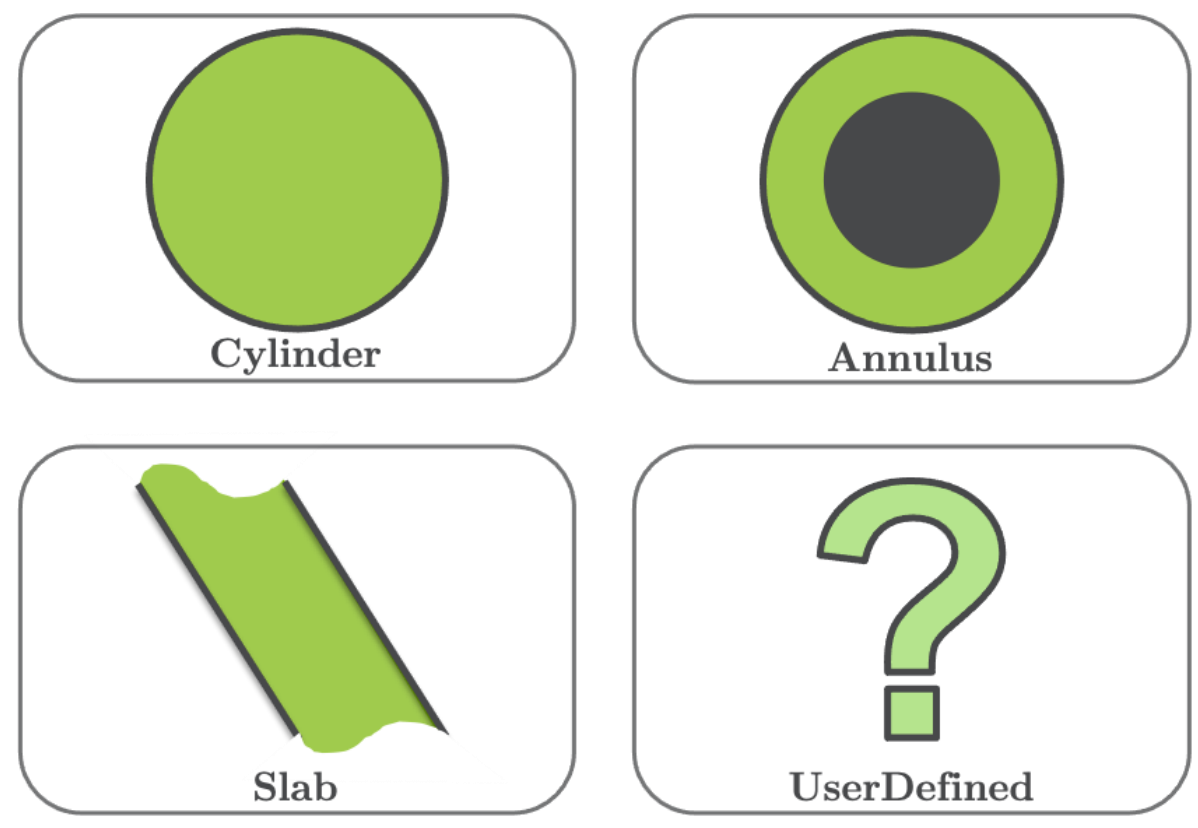

Figure 2-6. Geometry options for radiative enclosures built into the radiative heat transfer SAM Component

The Rad++ component centers itself around the enclosure geometry input. This core specifier determines how many surfaces will be interacting in the system, how these surfaces interact with each other and any potential participating fluid, and which other inputs are required. Additionally, this geometry-centric input framework acts to guide users to think about radHT in terms of radiative enclosures. Since Rad++ is structured upon the net radiation method, a method for radiative enclosures, thinking about radHT in terms of enclosures can help to avoid user errors when applying Rad++ to system models. Figure 2-6 shows the user options available for the enclosure geometry. If Annulus is chosen, then inner radius and width will be required; if Slab is chosen, then width will be required; and if Cylinder is chosen, diameter will be required. The UserDefined geometry is provided as an alternative to the predefined enclosure geometry options. This option requires more inputs, which will be described next. 


\subsubsection{Surface-specific inputs}

First and foremost, the radiatively interacting surface(s) must be specified. The number of surfaces provided must align with that stipulated by the chosen enclosure geometry. Ensuing surface inputs include spectrally-averaged radiative properties (user-calculated), surface areas, and view factors. If no radiative properties are specified, the surfaces are considered black $(\varepsilon=$ 1). If only emissivities are specified, the surface will be considered grey $(\rho=1-\varepsilon)$. Reflectivities can be specified along the lines of the non-grey discussion provided in the previous section. Surface areas are only necessary in two cases. If there is a participating fluid, the surface area for each interacting surface must be provided because the Rad++ Equation (10) for the fluid heat source requires surface areas. The other case is the multi-surface UserDefined scenario, in which three inputs are required: surface area for surface 1, surface area for surface 2 , and the view factor from surface 1 to surface 2 . These are necessary to calculate all other view factors.

\subsubsection{Fluid-specific inputs}

If the radiatively interacting system includes a participating fluid, the appropriate fluid component must be stipulated. Listing a fluid component will signify to Rad++ that a participating fluid is present. Depending on the modeled scenario, Rad++ will require further input(s) to determine the level of fluid interaction in the enclosure. If a predefined enclosure geometry is selected, the user can benefit from code-calculated fluid transmittance and emittance values. The only required input is the spectrally-averaged absorption coefficient, which needs to be determined by the user. However, if the user desires to override any transmittance or emittance values, the parameter to be overridden simply needs be input.

A UserDefined radiative geometry necessitates more inputs. For a single-surface UserDefined enclosure, either transmittance or emittance from surface 1 to itself needs to be stipulated. If the user inputs transmittance, emittance will be found by $\bar{\alpha}=1-\bar{t}$. If the user inputs emittance, transmittance will be found as $\bar{t}=1-\bar{\alpha}$. Again, an optional non-grey modeling scenario is available if the user so desires. For this option, both transmittance and emittance need to be specified. The only difference for a multi-surface UserDefined geometry is that the same process will need to be carried out for transmittance/emittance from surface 1 to surface 2 and for transmittance/emittance from surface 2 to itself. If a surface does not view itself, then the emittance between that surface and itself is equal to 0 .

\subsection{Testing of the radiative heat transfer component}

Test cases were carried out to investigate the effectiveness of SAM's new simulation capabilities to transfer energy radiatively for all desired scenarios originally shown in Table 2-1, including unprecedented simulation capabilities for SAM. Tests in Section 2.4.1 through 2.4.3 were conducted with a heat transfer coefficient of 0 , which meant no convective heat transfer - only radHT between the surfaces and conduction within each heat structure.

Initial conditions and thermophysical properties are included to facilitate reproducibility. However, the conditions imposed upon these tests generate results that are numerically unimportant. These conditions elicit behavior qualitatively relevant to the demonstration of SAM's radHT capabilities. SAM radHT modelers can utilize a large variety of initial conditions and physical properties to reproduce the behavior pertinent to this analysis. 


\subsubsection{Concentric pipes energy balance testing for solid-to-solid coupling}

In this test problem, two black concentric pipes were coupled together in an annular radiative cavity. Looking at Figure 2-7, the grey space between pipes shows where adjacent surfaces are interacting via radHT. Both pipes utilized adiabatic boundary conditions on their non-interacting wall surfaces. Based on the initial temperatures and volumetric heat capacity of the walls, some steady state homogeneous temperature should be reached based on energy conservation. These tests were also used to make sure the code was calculating proper view factors.

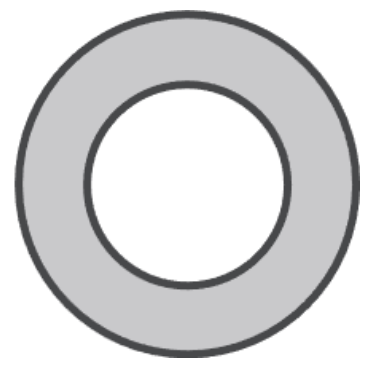

Figure 2-7. Concentric pipes with a radiation field between radiatively interacting surfaces

Table 2-2 shows the analytically temperature solutions based on pipe masses and initial temperatures. For all tests, the width of both heat structures remained $0.1 \mathrm{~m}$. Each simulation was carried out until the temperature difference between pipes fell within $0.005^{\circ} \mathrm{C}$ of its steadystate value. For each test case, the Rad++ simulation in SAM produced solid temperatures identical to those shown in Table 2, thereby validating solid-to-solid radHT for the annular enclosure geometry.

Table 2-2. Geometric parameters, initial conditions, and analytical temperature solutions for concentric pipes testing.

\begin{tabular}{crrrrr}
\hline Test & $r_{o, 1}[m]$ & $r_{i, 2}[m]$ & $T_{0,1}\left[{ }^{\circ} \boldsymbol{C}\right]$ & $T_{0,2}\left[{ }^{\circ} \boldsymbol{C}\right]$ & $\boldsymbol{T}_{\boldsymbol{S S}}\left[{ }^{\circ} \boldsymbol{C}\right]$ \\
\hline 1 & 0.1 & 0.1001 & 1200 & 400 & $\mathbf{5 9 9 . 9}$ \\
2 & 0.3 & 0.5 & 1200 & 400 & $\mathbf{9 0 8 . 6 7}$ \\
3 & 0.5 & 0.9 & 226.85 & 1226.85 & $\mathbf{9 0 5 . 4 2}$ \\
4 & 0.2 & 100 & 226.85 & 1226.85 & $\mathbf{1 2 2 5 . 3 5}$ \\
\hline
\end{tabular}




\subsubsection{Slab enclosure testing demonstrating convergence to analytical solution}

For this test, an analytical solution was found for a slab-type enclosure. Figure 2-8 shows an axial view of the two slab walls and fluid. All components are $1 \mathrm{~m}$ in length. The surface properties, surface temperatures, and fluid temperature shown in Table 2-3 were contrived and implemented in Equation (9). Note the non-grey Surface 2. The analytically found heat fluxes were then calculated and implemented in the SAM model by applying them as boundary conditions of the non-radiatively-interacting slab surfaces. For these plates to converge to the desired temperatures shown in Table $3,38568 \mathrm{~W} / \mathrm{m}^{2}$ was applied to the outer boundary of the wall which contains Surface 1, while $28029 \mathrm{~W} / \mathrm{m}^{2}$ was removed from the outer boundary of the wall which contains Surface 2.

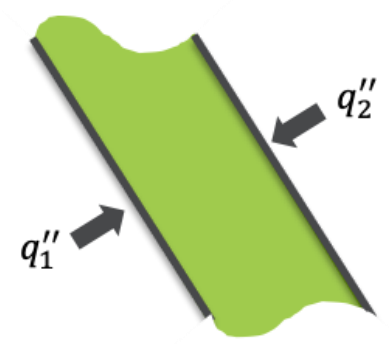

Figure 2-8. Semi-infinite slab geometry with participating fluid flowing between parallel walls

To keep fluid temperature constant along the slab in the flow direction, and therefore maintain the analytical solution along the walls, the fluid thermal inertia was set to $10^{8} \mathrm{~J} / \mathrm{m}^{3} \cdot \mathrm{K}$ and the fluid velocity was set to $0.1 \mathrm{~m} / \mathrm{s}$. For comparison, the walls' thermal inertias were set to $1586.9 \mathrm{~J} / \mathrm{m}^{3} \cdot \mathrm{K}$ with a thermal conductivity of $1500 \mathrm{~W} / \mathrm{m} \cdot \mathrm{K}$. However, the walls' thermophysical properties are arbitrary to the steady-state surface temperatures observed in this test. Altering these parameters would simply affect the time taken to reach steady state and the temperature gradients across the walls.

Table 2-3. Radiative parameters and analytical temperature solution for slab enclosure testing example.

\begin{tabular}{|c|c|c|c|}
\hline \multirow[t]{2}{*}{$\begin{array}{r}\text { Radiating } \\
\text { Body }\end{array}$} & \multicolumn{2}{|c|}{$\begin{array}{r}\text { Radiative } \\
\text { Properties }\end{array}$} & $\boldsymbol{T}_{S S}\left[{ }^{\circ} \mathrm{C}\right]$ \\
\hline & $\varepsilon$ & $\rho$ & \\
\hline Surface 1 & 0.8 & 0.2 & 800 \\
\hline \multirow[t]{2}{*}{ Surface 2} & 0.5 & 0.3 & 400 \\
\hline & \multicolumn{2}{|c|}{$\kappa\left[m^{-1}\right]$} & \\
\hline Fluid & & 5 & 600 \\
\hline
\end{tabular}

Regardless of the walls' initial temperatures $\left(500{ }^{\circ} \mathrm{C}\right.$ and $700{ }^{\circ} \mathrm{C}$ respectively), the radiating surfaces should converge to the temperature values used in calculation. Figure 2-9 shows the surfaces approaching the expected temperature values listed in Table 2-3. 


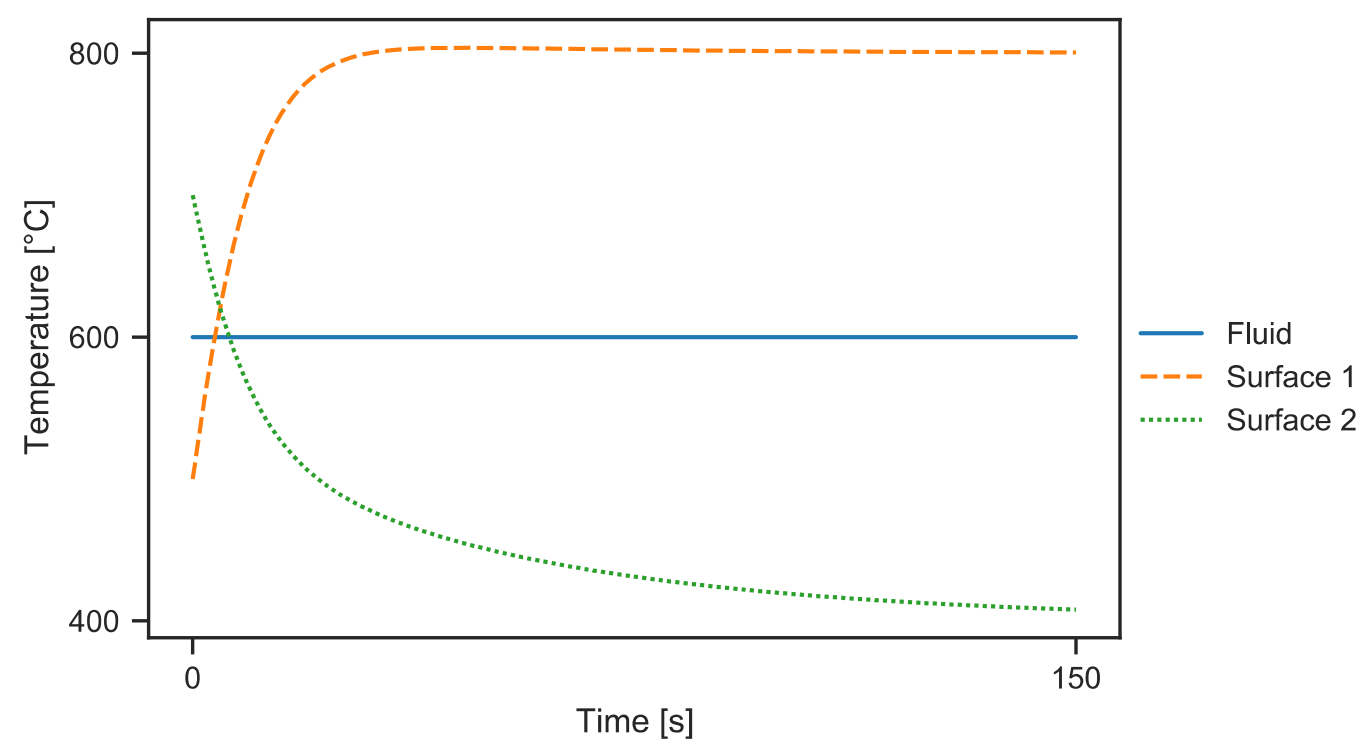

Figure 2-9. Radiating bodies converging to analytical solution in slab enclosure testing

This scenario is additionally notable in justifying the approach chosen for SAM radHT modeling. One other method utilized in TRACE implements surface-to-fluid radHT via a modification to the convective heat transfer coefficient. If that method had been implemented in SAM, the inner surface temperature would not have been allowed to rise above the fluid temperature. As the fluid-surface temperature difference approaches 0 , the heat transfer coefficient required to increase the surface temperature hurdles towards infinity, and no heat transfer coefficient value could force the surface to gain heat. In other words, modeling this radHT scenario with convective heat transfer would not allow the inner surface to switch from being colder to being hotter than the fluid. 


\subsubsection{Pipe flow demonstrating heating and cooling of walls by radiating fluid}

This single-surface with participating fluid test was executed to demonstrate both heating and cooling of a surface via radiative transfer with a fluid. Adiabatic outer surface conditions were imposed to ensure all heat transfer occurs via thermal radiation. The thermophysical properties of the pipe were manipulated so the surface's temperature oscillations would more closely resemble that of the fluid (see Figure 2-11): thermal conductivity is set to $2 \mathrm{~W} / \mathrm{m} \cdot \mathrm{K}$ and thermal inertia is set to $10^{4} \mathrm{~J} / \mathrm{m}^{3} \cdot \mathrm{K}$. Both the fluid and pipe are initialized at $600{ }^{\circ} \mathrm{C}$. The incoming fluid travels through the pipe at a velocity of $0.05 \mathrm{~m} / \mathrm{s}$ with a temperature profile which follows $T\left[{ }^{\circ} \mathrm{C}\right]=600+\sin (0.5 \cdot t)$.

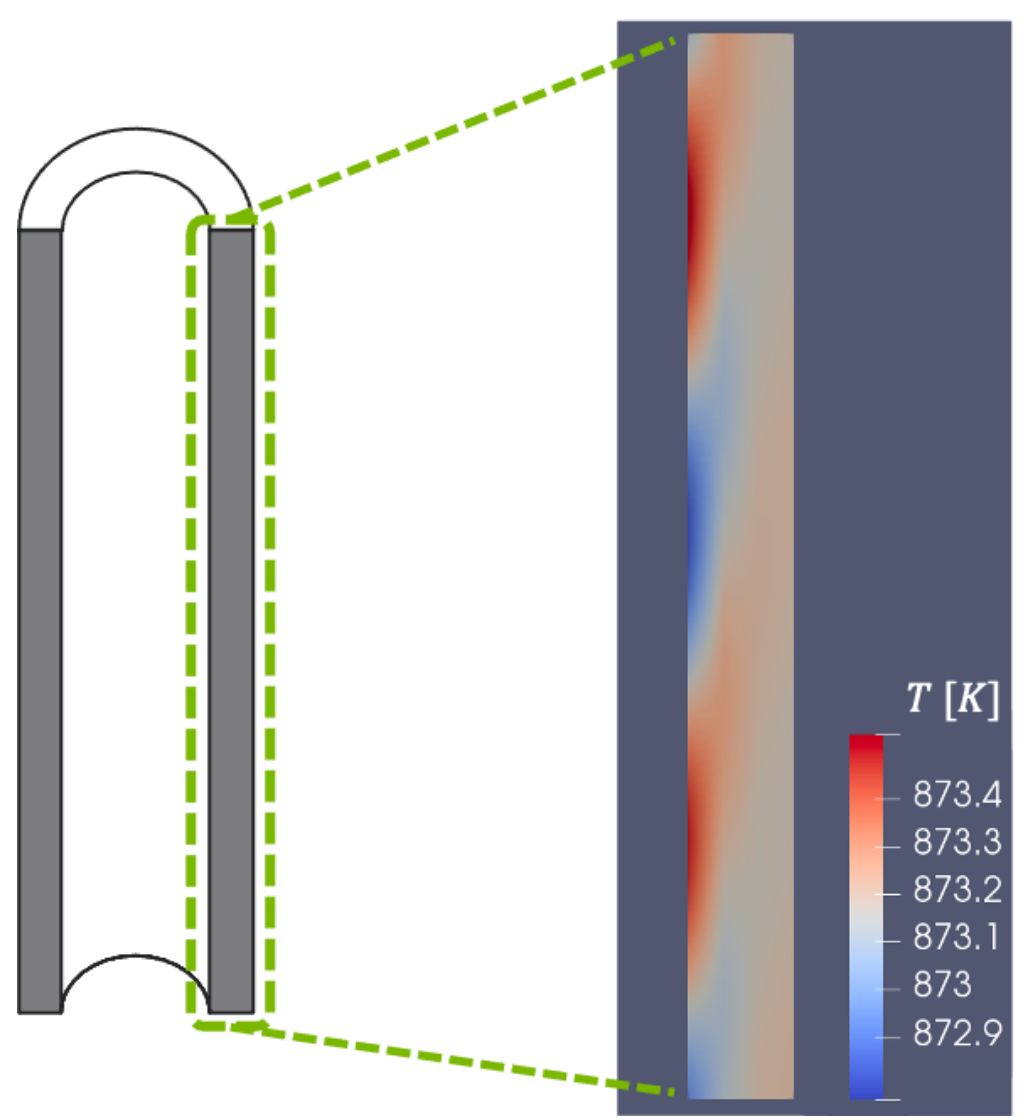

Figure 2-10. Wall temperature profile at time $=100 \mathrm{sec}$ in pipe heating and cooling testing 


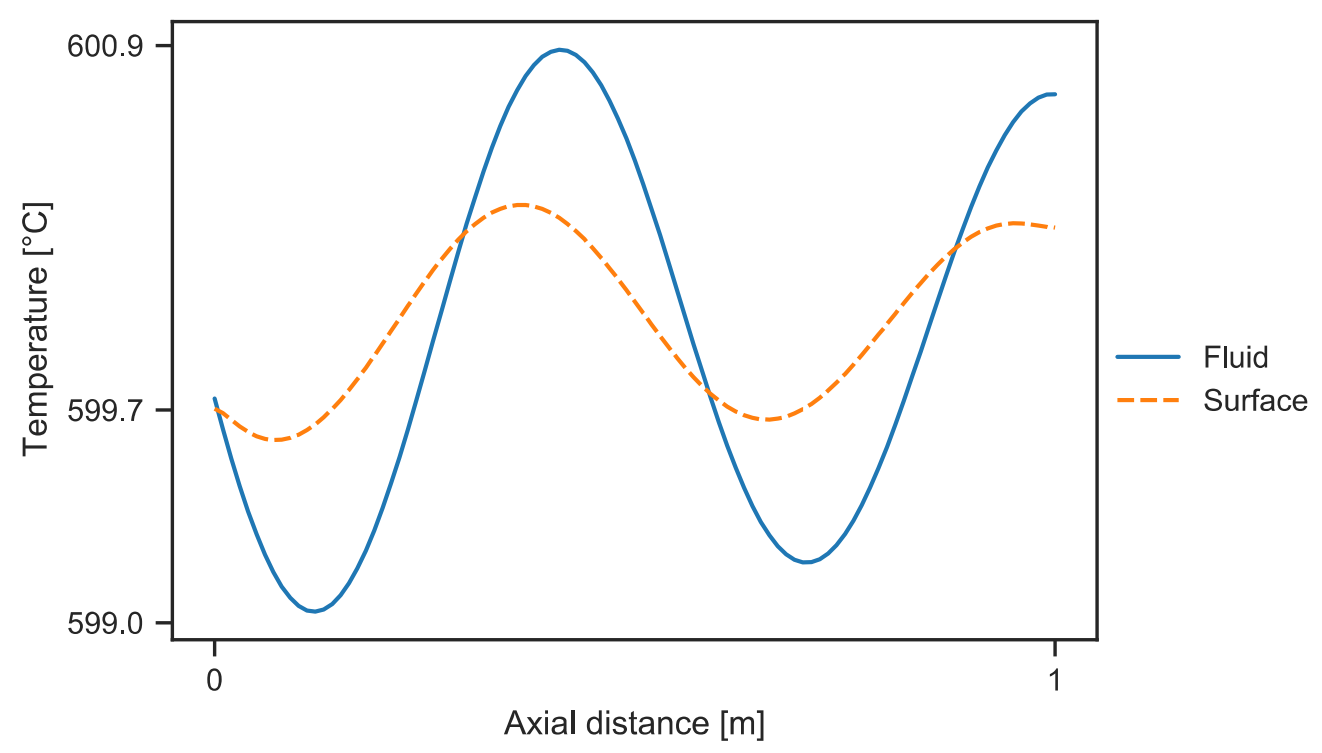

Figure 2-11. Axial temperature profiles demonstrating surface heating and cooling by the fluid in pipe heating and cooling testing.

Figure 2-10 and Figure 2-11 are both snapshots of temperature profiles at some moment during the test, which periodically repeats throughout the course of the entire $100 \mathrm{~s}$ simulation. Figure 2-10 clearly shows the participating fluid can both heat and cool the pipe surface. Looking at Figure 2-11, the regions of surface heating and cooling along the length of the test section can be demarcated by observing the temperature difference between the solid and fluid.

\subsection{Conclusions}

Following the development of an implementation strategy for SAM radHT modeling, new simulation capabilities have been built in SAM. The approach to modeling radHT, in addition to its implications on the user framework, were discussed.

The performed test cases demonstrate the expected behavior in all simulated scenarios. The first test alone proves the ability of Rad++ to couple two surfaces via radHT. The following tests do well to exhibit the behavior of SAM's newly developed modeling capabilities. Rad++ is demonstrated to produce the desired behavior for all test cases. This statement holds equally true for the scenarios in which analytical solutions are compared to the simulation results.

Future work will include enabling radHT simulation in other SAM Components. Additionally, the developed capabilities will be utilized for FHR applications, such as modeling radHT in molten-salt-filled downcomers and including thermal radiation in SAM models of the UCB Mk-1 design. 


\section{Closure Models Improvements for Molten Salt Heat Transfer}

As the FHR designs employing pebble bed reactor geometries and molten salts as the working fluid approach greater maturity, there is a need for additional considerations in the systems-level modeling performed in SAM to support such modeling efforts. Accurate representation of convective heat transfer through appropriate closure models for the 1-D governing flow equations are needed to properly assess the safety and economic feasibility of these advanced reactor designs. Previous work in the multi-dimensional porous medium flow model in SAM introduced relevant convective heat transfer correlations for packed bed geometries [6]. More recent work improved on the one-dimensional flow model to allow for modeling of heat conduction in 1-D spherical geometric structures with conjugate convective heat transfer to an adjacent 1-D fluid flow region [7]. Correlations for prediction of packed bed flow wall friction pressure drop were also added to the 1-D fluid model, which altogether provide a foundation for the improvements to heat transfer closure modeling discussed in the present work. A selection of relevant heat transfer correlation models for molten salt flow and pebble bed geometries added to SAM is presented in Section 3.1. Verification and demonstration of the selected correlations implemented into the 1-D fluid model in SAM is further discussed in Section 3.2.

\subsection{Selected convective heat transfer correlations}

\subsubsection{Pebble bed heat transfer correlations}

The Nusselt correlation developed by Wakao and Kaguei [16] was first determined from pebble bed mass transfer experimental measurement using a mass-heat transport analogy [17]. The developed correlation was also confirmed with a large set of steady and transient heat transfer experiment data. This is a commonly adopted correlation for pebble bed convective heat transfer, having been suggested and applied by numerous authors [18-21] and has been included as a user selectable model for its comparability to other system code analyses and familiarity to users who simulate pebble bed flows. Although initially developed with gas fluids, Huddar [18] was able to demonstrate experimentally that this correlation was able to model convective heat transfer within $\pm 15.4 \%$ using Drakesol 260 AT synthetic oil as a surrogate fluid for molten salt. The Wakao correlation is given below:

$$
\mathrm{Nu}=2+1.1 \operatorname{Re}_{p}^{0.6} \operatorname{Pr}^{\frac{1}{3}}
$$

The reported validity region of the Wakao correlation is $15<\operatorname{Re}_{p}<8500,0.7<\operatorname{Pr}<1$. Many pebble bed convective heat transfer correlations adopt a modified Reynolds number to reflect the characteristic length of the pebble bed flow geometry. The pebble bed Reynolds number $\operatorname{Re}_{p}$ and the corresponding heat transfer coefficient $h$ is defined by the pebble diameter $d_{p}$ and superficial velocity $v$ as shown below:

$$
\operatorname{Re}_{p}=\frac{\rho v d_{p}}{\mu}, \quad h=\frac{\mathrm{Nu} k}{d_{p}}
$$

In addition, a Nusselt correlation developed by the KTA [22] was produced from efforts to support High-Temperature Gas-cooled Reactor (HTGR) licensing in Germany, whose designs adopt a pebble bed core geometry with a gas coolant such as helium. This correlation was 
developed through a review of published data and correlations from roughly 30 papers to capture the convective heat transfer from pebble to fluid and considers the effect of the bed porosity $\varepsilon$. Although this correlation was originally developed for gas fluids, Liu et al [23] have demonstrated its applicability to high-Pr fluids, predicting within $\pm 10-25 \%$ while also using Drakesol 260AT synthetic oil as a surrogate fluid for molten salt in experimental work. This correlation has been previously adopted in the multidimensional fluid model in SAM [1] and has been selected as the default model for calculating the Nusselt number when a pebble bed is specified for the heat transfer geometry in a 1D fluid component. The KTA correlation is given below:

$$
\mathrm{Nu}=1.27 \frac{\operatorname{Pr}^{\frac{1}{3}}}{\varepsilon^{1.18}} \operatorname{Re}_{p}{ }^{0.36}+0.033 \frac{\operatorname{Pr}^{\frac{1}{2}}}{\varepsilon^{1.07}} \operatorname{Re}_{p}{ }^{0.6}
$$

The reported validity region of the KTA correlation is $100<\operatorname{Re}_{p}<10000,0.36<\varepsilon<0.42$, $D_{\text {bed }} / d_{p}>20$ (pebble bed to pebble diameter ratio), and $H_{b e d} / d_{p}>4$ (pebble bed height to pebble diameter ratio). This correlation was developed for gas coolants, in this case with a $\mathrm{Pr}=$ 0.7 . The reported uncertainty of this correlation is $\pm 20 \%$ with a confidence level of $95 \%$.

It is also important to consider the heat transfer between the pebble bed and the surrounding wall or reflector, which in many pebble bed reactor designs is composed of a relatively thick graphite structure. Heat transfer from the pebble bed to the wall determines the temperature of the reflector wall and its thermal inertia under normal operation. More importantly, during transient scenarios this mode of heat transfer may be important for decay heat removal from the pebble bed, as heat moves radially outward to reactor cavity cooling systems (RCCS). The modeling of pebble bed-to-wall heat transfer has been considered in several empirical correlations, such as those by Yagi and Wakao [24] and Achenbach [25]. Specifically in SAM, this pathway of heat transfer has been considered and treated in the multidimensional flow model in previous work [6], in which the Achenbach correlation has been adopted as it also considers the effect of the bed diameter [1]:

$$
\mathrm{Nu}=\left(1-\frac{\mathrm{d}_{\mathrm{p}}}{\mathrm{D}_{\text {bed }}}\right) \operatorname{Re}_{p}{ }^{0.61} \operatorname{Pr}^{\frac{1}{3}}
$$

which is valid for $50<\operatorname{Re}_{p}<20000$.

In the multidimensional flow model treatment in SAM, two important assumptions had to be made and justified, since the original development of the Yagi and Wakao considered the pebble and fluid to be in thermal equilibrium, which is not applicable in the case of a pebble bed reactor core where heat is generated in the pebbles and cooled by the fluid [6]. The first assumption is that all heat transfer between the pebble bed and wall can be adequately captured as heat transfer between the wall and the fluid, as the contribution of heat transfer from wallto-pebble is comparatively much smaller. The second assumption is with regards to the treatment of solid temperatures at the pebble-wall interface. In the multidimensional model, since the pebble bed is represented as a continuous solid phase, the distribution of temperature across the entire core radius is modeled and thus an interfacial boundary condition is applied to additionally ensure a more physically realistic continuous temperature from the pebble to the reflector wall. However, in the 1D model implementation [7] only the radial temperature distribution within a single average pebble is considered, representing all pebbles in each axial 
node with the same average temperature profile. Therefore, it would not be appropriate to apply a similar continuity interface boundary condition, and it is necessary to assume in the 1D model that all heat transfer from pebble bed to reflector wall is transferred through convective heat transfer in the fluid, necessitating an applicable correlation to capture this mode of heat transfer.

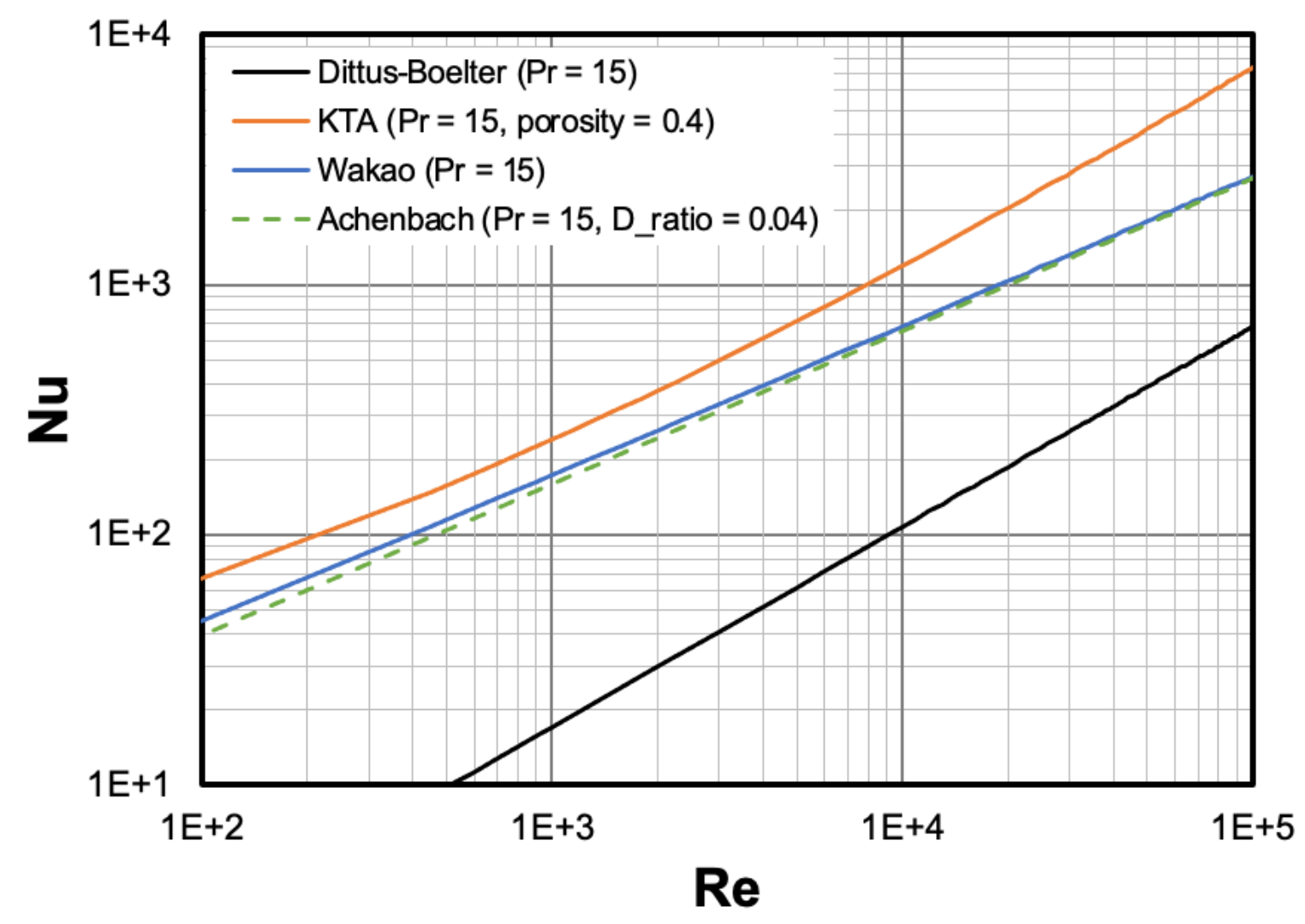

Figure 3-1. Comparison of Nusselt number as calculated by the KTA, Wakao, and Achenbach pebble bed flow correlations against the standard Dittus-Boelter value at equivalent Re.

\subsubsection{Molten salt heat transfer correlations}

As discussed previously in Section 2, employing molten salts as the working fluid coolant in advanced reactors requires additional considerations due to its higher operating temperatures and different heat transfer characteristics not considered in a typical LWR system analysis. In their operating temperature range of $700-900{ }^{\circ} \mathrm{C}$, molten salts have a relatively higher Prandtl number of about $\operatorname{Pr}=10-20$ as compared to pressurized water $(\operatorname{Pr}=5)$ or helium $(\operatorname{Pr}=0.7)$, indicating thermal diffusivity in the fluid is lower compared to its convective momentum diffusivity. In SAM, several correlations have been included in consideration of low-Prandtl fluids such as liquid metals ( $\operatorname{Pr}<0.1$ ), prompting an assessment of the existing set of correlations for general fluids. For fluids with $\operatorname{Pr}>0.1$ in typical forced convection, convective heat transfer is calculated by the well-known Nusselt correlation developed by Dittus and Boelter [26]: 


$$
\mathrm{Nu}=0.023 \operatorname{Re}^{0.8} \operatorname{Pr}^{n}, \quad \mathrm{n}=\left\{\begin{array}{l}
0.4 \text { (heating) } \\
0.33 \text { ( cooling) }
\end{array}\right.
$$

Notably, the classic Dittus-Boelter equation is valid for turbulent flow of $\operatorname{Re} \geq 10000$ and for general fluids with $0.6 \leq \operatorname{Pr} \leq 160$ and an uncertainty of $\pm 15 \%$, for which molten salt fluids would fall within its valid range for appropriate flow conditions. Adopting a similar methodology to RELAP5 [15] to account for laminar and natural convective flows, SAM will use the maximum heat transfer coefficient as calculated by the Dittus-Boelter correlation, the Sellars laminar flow correlation [1]:

$$
\mathrm{Nu}=\frac{48}{11} \cong 4.36 \text { for } \mathrm{Pe}<10
$$

and the Churchill-Chu correlation for natural convection adjacent to a vertical plane:

$$
\mathrm{Nu}=\left[0.825+\frac{0.387 \mathrm{Ra}^{\frac{1}{6}}}{\left(1+(0.492 / \mathrm{Pr})^{\frac{9}{16}}\right)^{\frac{8}{27}}}\right]^{2}, \quad \text { for } \mathrm{Ra}<10^{12}
$$

Experimental work has been historically performed to quantify convective heat transfer characteristics of molten salt, with a large effort conducted by Oak Ridge National Laboratory (ORNL) in the 1950s and 1960s. Various authors have also made efforts to review or qualify appropriate correlations applicable to larger sets of experimental data [21, 27, 28], including more recent efforts by Yoder [29] at ORNL. The author demonstrates that comparing and fitting correlations to historical data sets is far from a trivial task, considering the range in quality of reported data and discrepancies in the underlying fluid property modeling that directly affect the calculation of non-dimensional numbers. As a result, there is a relatively large range of uncertainty in the measured data for molten salt heat transfer. A commonly cited Nusselt correlation in comparison to molten salt data is by Gnielinski [30] which is adopted in the TRACE system code [31] instead of Dittus-Boelter due to its enhanced accuracy in transition regime flows:

$$
\mathrm{Nu}=\frac{\left(\frac{f}{2}\right)(\operatorname{Re}-1000) \operatorname{Pr}}{1+12.7\left(\frac{f}{2}\right)^{\frac{1}{2}}\left(\operatorname{Pr}^{\frac{2}{3}}-1\right)}
$$

for which the friction factor $f$ is calculated using the formula for smooth tubes by Filonenko:

$$
f=[1.58 \ln (\operatorname{Re})-3.28]^{-2}
$$

The Gnielinski correlation is valid for the range of $2300 \leq \mathrm{Re} \leq 5 \times 10^{6}$ and $0.5 \leq \mathrm{Pr} \leq$ 2000. A comparison of the Dittus-Boelter and Gnielinski correlations is shown in Figure 3-2 for fluids with Prandtl numbers of 5 and 30, illustrating the deviation of the two correlations towards the transition regime down to the Sellars laminar Nusselt correlation value. Several authors in their respective reviews have found that correlations developed for generic fluids (i.e. water, air, etc.) have reasonable ability to predict convective heat transfer in molten salt and commonly recommending the more recently-developed Gnielinski correlation. The justification for this recommendation is in part due to the high uncertainty in the measured data 
as well as in the heat transfer predictions of the correlations themselves, typically exhibiting an uncertainty of $\pm 15-20 \%$ that increases towards lower Reynolds number flow regimes. The Gnielinski correlation has been added to SAM as a user-specifiable option to facilitate model comparability in future analyses but will continue to rely on the existing correlations and logic as the default methodology for calculating heat transfer in general fluids ( $\operatorname{Pr}>0.1$ ).

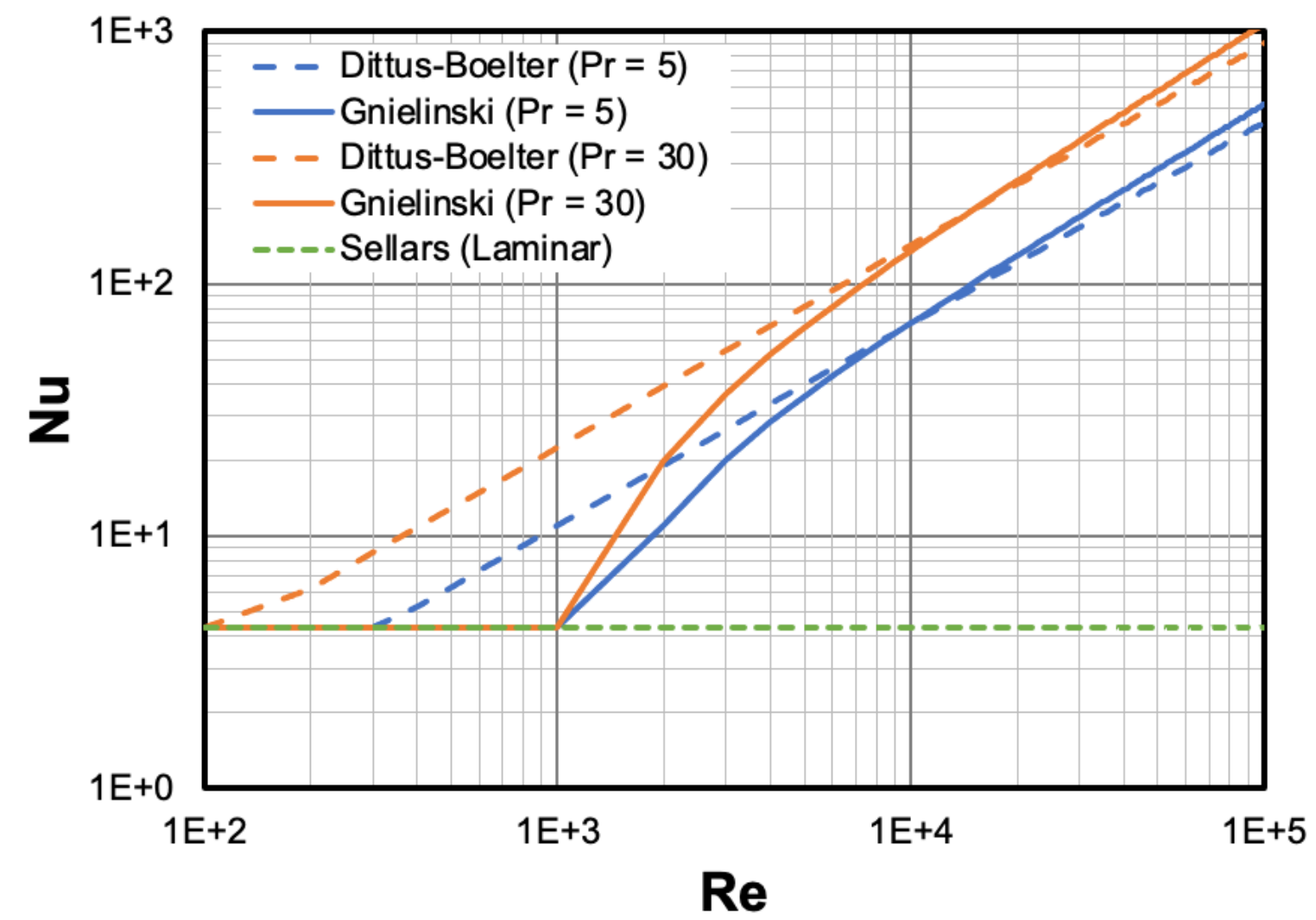

Figure 3-2. Comparison of Nusselt number as calculated by the Dittus-Boelter and Gnielinski correlations for a fluid with Prandtl number of 5 and 30, along with the minimum Nusselt value for laminar flow as determined by the Sellars correlation $(\mathrm{Nu}=4.36)$.

\subsection{Verification and demonstration of selected correlations}

An initial assessment was performed to verify the implementation of the additional pebbleto-fluid heat transfer correlations and estimate the potential impact on FHR system analyses, building upon previous efforts to improve 1D spherical heat conduction modeling in SAM [7]. In the first example, a simple horizontal pebble bed channel with constant boundary conditions and volumetric heat generation in the solid is modeled to demonstrate conservation of convective heat transfer across the channel. The fluid and solid domains are modeled as separate domains and the setup for this verification case is given below in Table 3-1and Figure 3-3. The material properties for the fluid and solid are also shown in Table 3-1 and were selected to fall within the valid ranges of the KTA, Wakao, and Dittus-Boelter correlations with a fluid Pr of 15 to generically mimic the anticipated fluid properties of a molten salt. Since the material properties are constant, the bulk fluid temperature $T_{\text {fluid }}$ and the pebble center temperatures $T_{\text {center }}$ over the channel axial length $x$ can be analytically derived in the following forms: 


$$
\begin{gathered}
T_{\text {fluid }}(x)=T_{\text {in }}+\frac{(1-\epsilon) q^{\prime \prime \prime} x}{\rho_{\text {in }} v_{\text {in }} C_{p}} \\
T_{\text {center }}(x)=T_{\text {fluid }}(x)+\frac{q^{\prime \prime \prime}}{3 \boldsymbol{h}} R+\frac{q^{\prime \prime \prime}}{6 k} R^{2}
\end{gathered}
$$

Table 3-1. Horizontal pebble channel verification problem setup.

\begin{tabular}{|l|l||l|l|}
\hline Parameter & Value & Material Property & Value \\
\hline Channel length $[\mathrm{m}]$ & 1.0 & Fluid density (at $850 \mathrm{~K})\left[\mathrm{kg} / \mathrm{m}^{3}\right]$ & 1000 \\
\hline Channel diameter $[\mathrm{m}]$ & 1.0 & Fluid enthalpy $($ at $850 \mathrm{~K})[\mathrm{J} / \mathrm{kg}]$ & $1.0 \times 10^{6}$ \\
\hline Flow area (pore space) $\left[\mathrm{m}^{2}\right]$ & 0.314 & Fluid thermal expansion $[1 / \mathrm{K}]$ & $1.0 \times 10^{-4}$ \\
\hline Porosity $\epsilon$ & 0.4 & Fluid heat capacity $[\mathrm{J} / \mathrm{K}]$ & 1500 \\
\hline Pebble diameter $R[\mathrm{~m}]$ & 0.06 & Fluid viscosity $[\mathrm{Pa}-\mathrm{s}]$ & $1.0 \times 10^{-3}$ \\
\hline Inlet temperature $[\mathrm{K}]$ & 850 & Fluid conductivity $[\mathrm{W} / \mathrm{m}-\mathrm{K}]$ & 0.1 \\
\hline Inlet (superficial) velocity $[\mathrm{m} / \mathrm{s}]$ & 0.5 & Pebble conductivity $[\mathrm{W} / \mathrm{m}-\mathrm{K}]$ & 5.0 \\
\hline Outlet pressure $[\mathrm{Pa}]$ & $1.0 \times 10^{5}$ & Pebble density $\left[\mathrm{kg} / \mathrm{m}^{3}\right]$ & 1000 \\
\hline Vol. heat source $q^{\prime \prime \prime}\left[\mathrm{W} / \mathrm{m}^{3}\right]$ & $1.0 \times 10^{7}$ & Pebble heat capacity $[\mathrm{J} / \mathrm{K}]$ & 100 \\
\hline
\end{tabular}

808080808080808080808080808080808

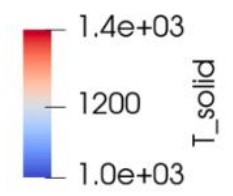

Figure 3-3. Horizontal pebble bed channel verification model with fluid domain (top) and averaged "stacked" spherical pebble coupled solid domain (bottom) shown with their simulated temperature profiles.

The steady pebble solid temperature is dictated by the convective heat transfer coefficient $\boldsymbol{h}$ in Equation (21) and was used verify the correct implementation of the selected correlations. This verification case was simulated as a steady state problem in SAM with 20 axial elements in the fluid and solid domains and 20 radial elements in the solid domain. The pebble centerline temperatures calculated by SAM using the KTA, Wakao, and original Dittus-Boelter correlations agreed with their analytical solutions within an error on the order of $10^{-4}$ as demonstrated in Figure 3-4. The radial temperature distributions at the core outlet are shown in Figure 3-5. It was also confirmed that the Dittus-Boelter significantly underpredicts convective heat transfer in the 1D pebble bed flow component and fails to account for the enhanced heat transfer induced by the tortuous fluid path, whereas the KTA and Wakao models had a relatively similar predicted value. 


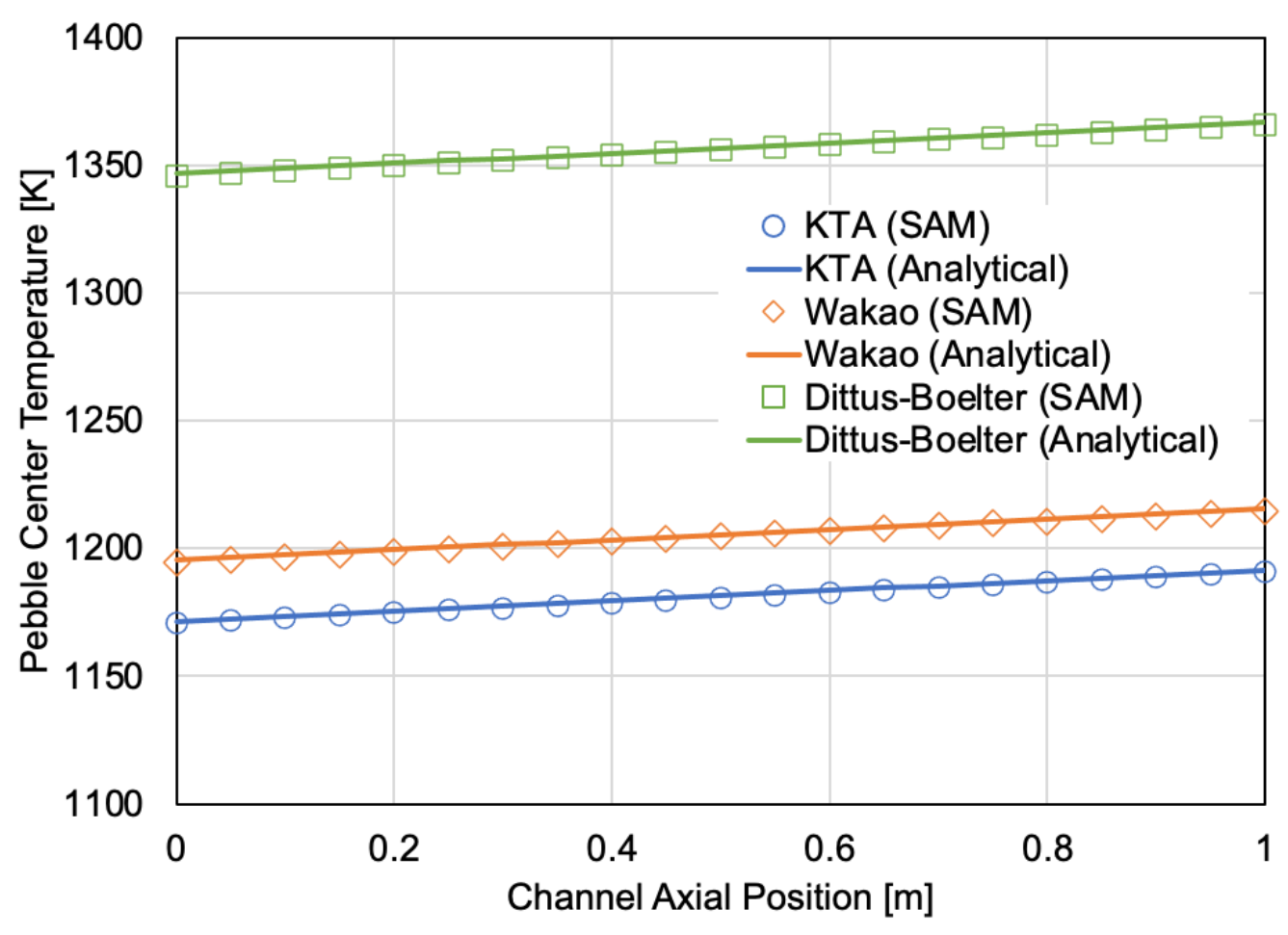

Figure 3-4. Pebble center temperature over the axial length of a horizontal pebble bed, comparing different correlations for pebble-fluid convective heat transfer.

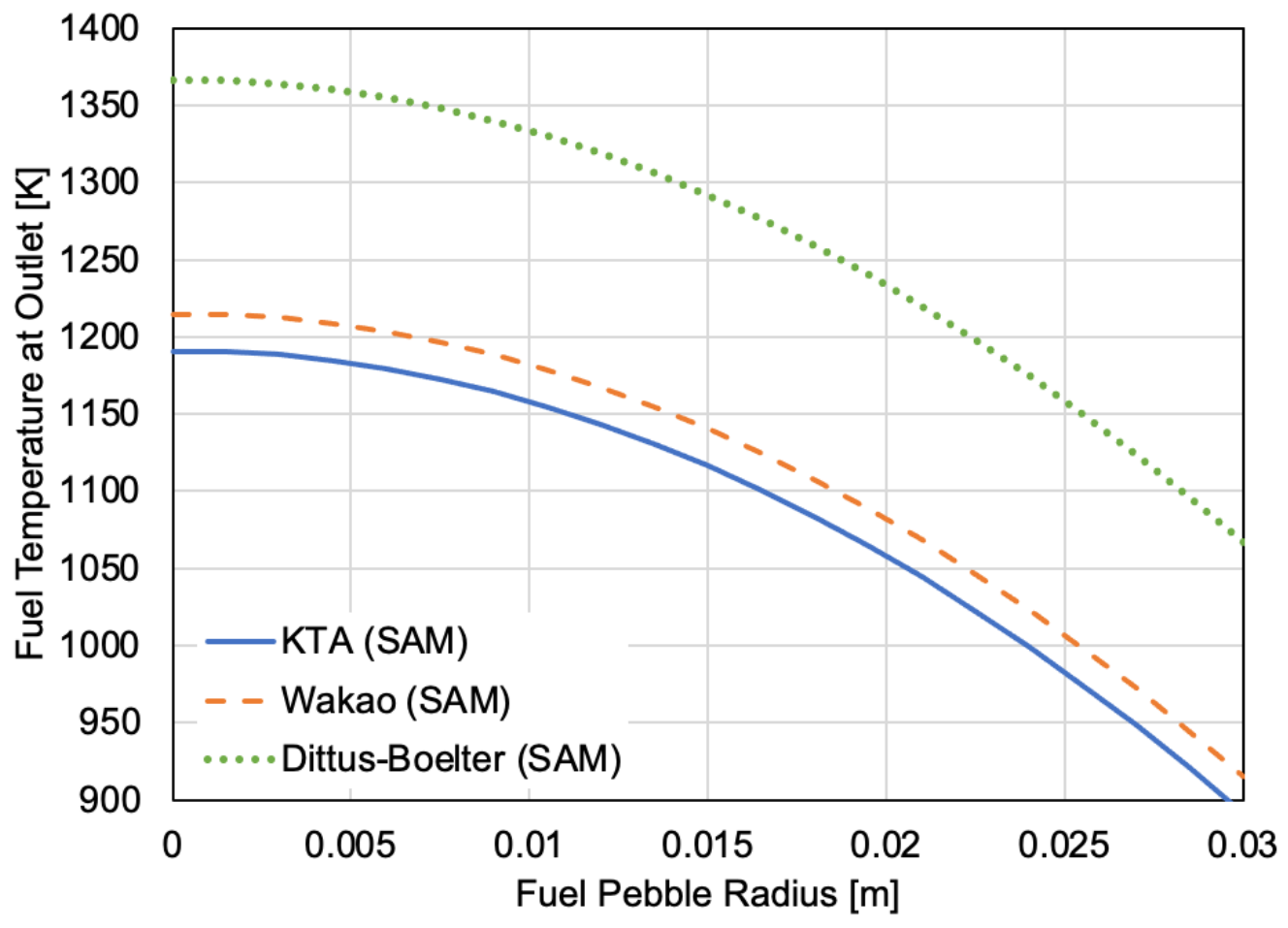

Figure 3-5. Radial temperature profile of an average pebble at the outlet of a horizontal pebble bed, comparing different correlations for pebble-fluid convective heat transfer. 
To assess the impact of the added KTA and Wakao correlations, a demonstration was carried out using a steady-state simulation of a generic reference FHR model developed in SAM to simulate the active core region of a pebble-bed fluoride-salt-cooled high temperature reactor (PB-FHR). This model was originally developed in FY2020 [6] and updated in FY2021 [7] to generally capture design aspects of the University of California, Berkeley (UCB) Mark-1 design and Kairos Power gFHR benchmark design. A diagram of core dimensions is shown in Figure 3-6 with select reactor parameters and conditions at hot full power given in Table 3-2.

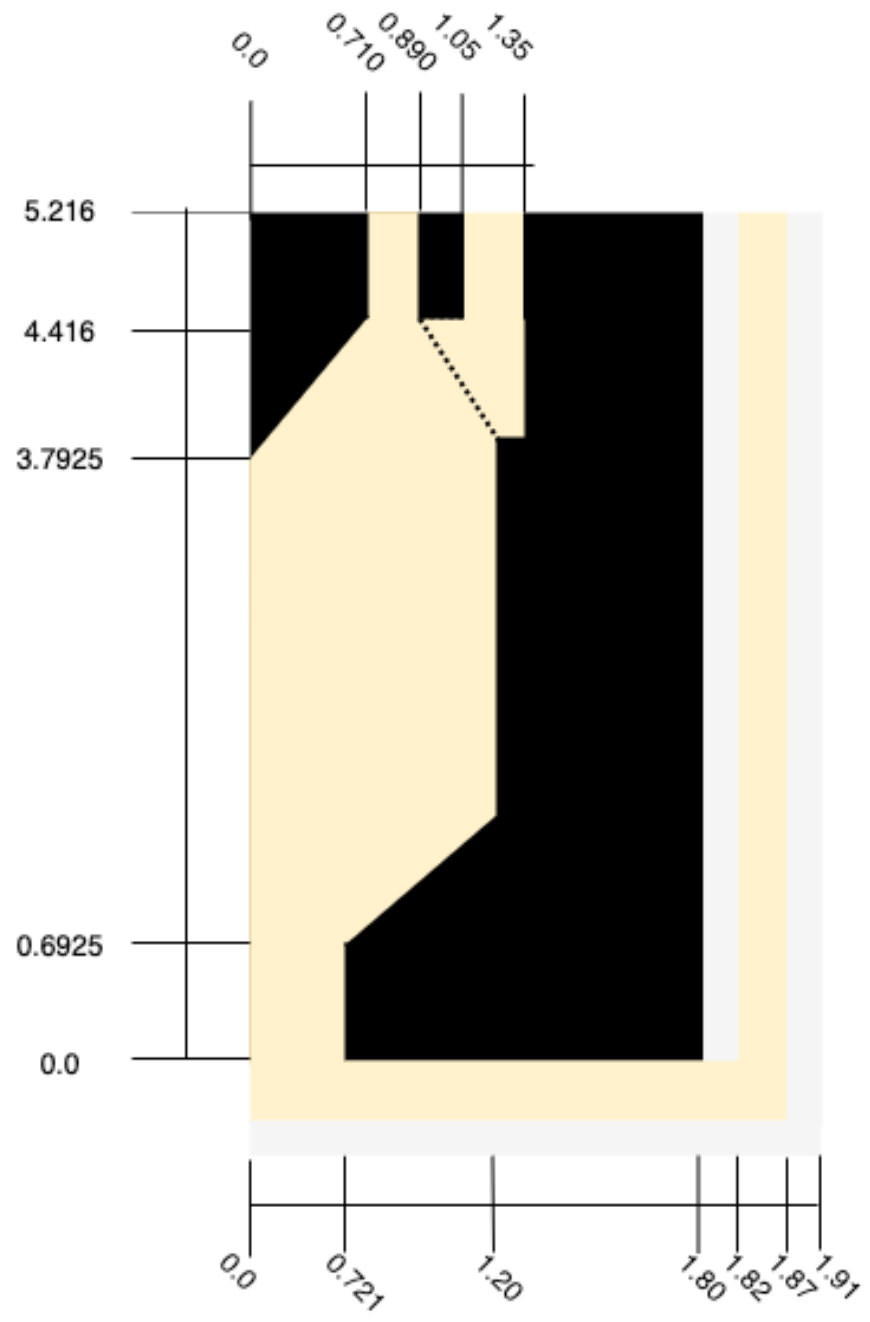

Figure 3-6. Dimensions of a generic PB-FHR reactor core [7]. 
Table 3-2. Dimensions and operating parameters of the SAM generic reference FHR [7].

\begin{tabular}{|l|l|}
\hline Parameter & Value \\
\hline Power [MW] & 320 \\
\hline Core Radius [m] & 1.2 \\
\hline Active Core Height [m] & 3.1 \\
\hline Porosity [\#] & 0.4 \\
\hline Vessel Thickness [cm] & 4 \\
\hline Downcomer Thickness [cm] & 5 \\
\hline Mass Flow Rate [kg/s] & 1324.6 \\
\hline Pebble Radius [cm] & 2 \\
\hline Low Density Graphite Thickness [cm] & 1.38 \\
\hline Fuel Layer Thickness [cm] & 0.42 \\
\hline Shell Layer Thickness [cm] & 0.2 \\
\hline
\end{tabular}

Previous improvements to the 1D spherical heat conduction modeling in SAM utilized a standalone active core model of the reference FHR example to demonstrate the effects of the fuel geometry modeling. Here, the previously developed model with the core region specified as an average 1D spherical pebble bed core channel and prescribed inlet/outlet boundary conditions is used to demonstrate the added convective heat transfer correlations. The KTA and Wakao correlations were specified for the core channel and compared to the original default calculation using the Dittus-Boelter correlation, with an identical steady full power and axial profile modeled in each case. The core channel model was simulated for a null transient of 1000 seconds to achieve a thermal-hydraulic steady state. Simulated temperatures over the axial length of the active core and radially at the core midplane are shown in Figure 3-7. In agreement with the horizontal pebble bed channel verification example, the convective heat transfer in the active core region is underpredicted by the original Dittus-Boelter correlation, resulting in an overprediction of approximately $75 \mathrm{~K}$ in the simulated fuel temperatures due to this limitation. The KTA and Wakao predictions were comparatively close, differing by approximately $10 \mathrm{~K}$ in the simulated fuel temperatures. Further work is needed to assess the impact of the convective heat transfer models in different transient scenarios. 

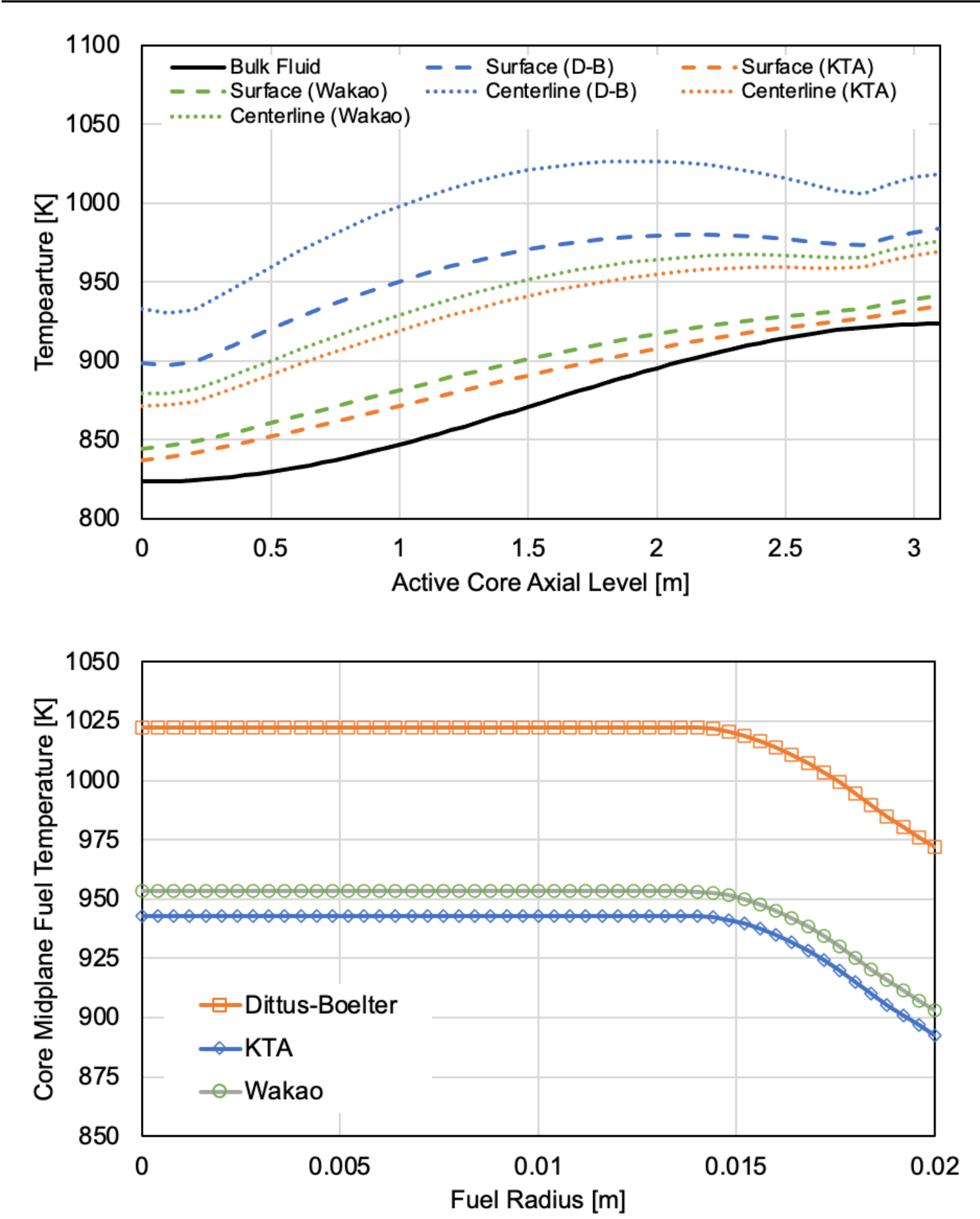

Figure 3-7. Comparison of axial average axial temperatures (top) and the average pebble radial temperature profile (bottom) at the core midplane $(z=1.55 \mathrm{~m})$ with the KTA, Wakao, and Dittus-Boelter (D-B) correlations. 


\section{Conclusions and Future Work}

In the present work, selected improvements were made to the one-dimensional modeling of heat transfer in SAM with the goal of better capturing phenomena specific to molten salt-cooled pebble bed reactors and improved system-level modeling capabilities of such reactor designs. As a result of the higher working temperatures associated with usage of molten salt coolant and ceramic pebble fuel forms, improved treatment of radiative heat transfer was necessarily incorporated into SAM. The new approach for radiative heat transfer can model the radiation between two structural surfaces and a molten salt fluid, which has a comparatively higher opacity and absorption of radiative heat than water. The added capability is designed to allow users to flexibly model spectrally and geometrically averaged radiative heat transfer in a cylindrical, slab, annular, or user-defined geometry, also incorporating methods to automatically calculate view factors to reduce the modeling burden on the users. Verification test cases were developed to demonstrate the different geometric options and overall ability to couple surfaces through the radiation heat transfer constraint system. Additionally, convective heat transfer correlations were selected from literature and included in SAM as user-specifiable model options, specifically to account for the enhanced heat transfer expected in pebble bed geometry flows. The implementation of these correlations was tested against a simple analytical verification model and demonstrated with a reference FHR example to show the improved accuracy in convective heat transfer and most critically prediction of the fuel temperature in a pebble bed core.

While the SAM code has been significantly improved in this area of heat transfer modeling for FHR designs, ongoing and future work is needed to further improve its capabilities, robustness, and user friendliness, including:

- Extension of radiative heat transfer to additional components in SAM;

- Completing the implemention of numerical stabilization scheme for the radiative heat transfer model in the fluid energy equation;

- Additional code validations of both the radiative and convective heat transfer models to relevant experiments and separate effect testing for FHR design applications and molten salt fluids;

- Further exploration of additional empirical correlations that may improve accuracy in convective heat transfer modeling, especially for advanced heat exchanger designs with enhanced convective heat transfer used in FHRs. 


\section{Acknowledgment}

Argonne National Laboratory's work was supported by the U.S. Nuclear Regulatory Commission under Task Order Agreement No. 31310019N0003, through U.S. Department of Energy contract DE-AC02-06CH11357. This material is also based upon work supported under a Department of Energy, Office of Nuclear Energy, Integrated University Program Graduate Fellowship.

This report was prepared as an account of work sponsored by an agency of the U.S. Government. Neither the U.S. Government nor any agency thereof, nor any of their employees, makes any warranty, expressed or implied, or assumes any legal liability or responsibility for any third party's use, or the results of such use, of any information, apparatus, product, or process disclosed in this report, or represents that its use by such third party would not infringe privately owned rights. The views expressed in this report are not necessarily those of the U.S. Nuclear Regulatory Commission. 


\section{References}

[1] R. Hu, "SAM Theory Manual," Argonne National Laboratory, ANL/NE-17/4, 2017.

[2] R. Hu, L. Zou, and G. Hu, "SAM User's Guide," Argonne National Lab.(ANL), Argonne, IL (United States), 2019.

[3] C. J. Permann et al., "MOOSE: Enabling massively parallel multiphysics simulation," SoftwareX, vol. 11, p. 100430, 2020.

[4] K. Ahmed, R. Scarlat, and R. Hu, "Benchmark Simulation of Natural Circulation Cooling System with Salt Working Fluid Using SAM," in NURETH-17, Xi'an China, 2017.

[5] H. Zhao, L. H. Fick, J. Herter, and B. Haugh, "Overview of Kairos Power Systems Code KP-SAM Development," presented at the NURETH-18, Portland OR, 2019.

[6] G. Hu, D. O'Grady, L. Zou, and R. Hu, "Development of a Reference Model for Molten-Salt-Cooled Pebble-Bed Reactor Using SAM," Argonne National Lab.(ANL), Argonne, IL (United States), ANL/NSE-20/31, 2020.

[7] D. O'Grady, T. Mui, A. Lee, L. Zou, G. Hu, and R. Hu, "SAM Code Enhancement, Validation, and Reference Model Development for Fluoride-salt-cooled Hightemperature Reactors," Argonne National Lab.(ANL), Argonne, IL (United States), ANL/NSE-21/15, 2021.

[8] L. Zou, D. O'Grady, G. Hu, and R. Hu, "Explicit Modeling of Pebble Temperature in the Porous-medium Framework for Pebble-bed Reactors Applications," Argonne National Lab.(ANL), Argonne, IL (United States), 2021.

[9] U. S. N. R. Commission, "TRACE V5.0 user's manual — volume 2: Modeling guideline," Washington, DC, USA, 2008.

[10] A. T. Cisneros, J. K. Choi, A. Y. Chong, M. Fratoni, and S. Hong, "Technical Description of the "Mark 1" Pebble-Bed Fluoride-Salt-Cooled High-Temperature Reactor (PB-FHR) Power Plant," in Tech. Rep.: Department of Nuclear Engineering, University of California Berkeley, 2014.

[11] D. L. Krumwiede, R. O. Scarlat, J. K. Choi, T. M. Phan, and P. F. Peterson, "Threedimensional modeling of the pebble-bed fluoride-salt-cooled, high-temperature reactor (PB-FHR) commercial plant design," in Proceedings of the American Nuclear Society 2013 Winter Meeting, 2013.

[12] B. Bendow, "Transparency of bulk halide glasses," Fluoride glass fiber optics, vol. 1, pp. 85-137, 1991.

[13] J. R. Howell, M. P. Mengüç, K. Daun, and R. Siegel, Thermal radiation heat transfer. CRC press, 2020.

[14] M. F. Modest, Radiative heat transfer. Academic press, 2013.

[15] C. Fletcher and R. Schultz, "RELAP5/MOD3 Code Manual. Volume 5, Users Guidelines," Nuclear Regulatory Commission, Washington, DC (United States). 1992.

[16] N. Wakao, S. Kaguei, and T. Funazkri, "Effect of fluid dispersion coefficients on particle-to-fluid heat transfer coefficients in packed beds: correlation of Nusselt numbers," Chemical engineering science, vol. 34, no. 3, pp. 325-336, 1979.

[17] N. Wakao and T. Funazkri, "Effect of fluid dispersion coefficients on particle-to-fluid mass transfer coefficients in packed beds: correlation of Sherwood numbers,"

Chemical engineering science, vol. 33, no. 10, pp. 1375-1384, 1978. 
[18] L. R. Huddar, "Heat Transfer in Pebble-Bed Nuclear Reactor Cores Cooled by Fluoride Salts," UC Berkeley, 2016.

[19] P. Avigni, A. Wysocki, and G. Yoder, "Liquid Salt Test Loop modeling using TRACE," Annals of Nuclear Energy, vol. 106, pp. 170-184, 2017.

[20] L. Liu, J. Deng, D. Zhang, and H. Gu, "Review of the experimental research on the thermal-hydraulic characteristics in the pebble bed nuclear reactor core and fusion breeder blankets," International Journal of Energy Research, 2020.

[21] R. R. Romatoski, "Fluoride-Salt-Cooled High-Temperature Test Reactor ThermalHydraulic Licensing and Uncertainty Propagation Analysis," Doctor of Philosophy, Nuclear Science and Engineering, Massachusetts Institute of Technology, 2017.

[22] N. S. S. Commission, "Reactor core design of high-temperature gas-cooled reactors. Part 3: Loss of pressure through friction in pebble bed cores," Nuclear Safety Standards Commission, Berlin, Germany, 1981.

[23] L. Liu et al., "Experimental investigation of flow and convective heat transfer on a high-Prandtl-number fluid through the nuclear reactor pebble bed core," Applied Thermal Engineering, vol. 145, pp. 48-57, 2018.

[24] S. Yagi and N. Wakao, "Heat and mass transfer from wall to fluid in packed beds," AIChE Journal, vol. 5, no. 1, pp. 79-85, 1959.

[25] E. Achenbach, "Heat and flow characteristics of packed beds," Experimental thermal and fluid science, vol. 10, no. 1, pp. 17-27, 1995.

[26] T. L. Bergman, F. P. Incropera, D. P. DeWitt, and A. S. Lavine, Fundamentals of heat and mass transfer. John Wiley \& Sons, 2011.

[27] S. Zhang, "Study of a Passive Decay Heat Removal System and Tritium Mitigation for Fluoride-salt-cooled High-temperature Reactors," Doctor of Philosophy, Nuclear Engineering and Radiological Sciences, University of Michigan, 2020.

[28] K. Britsch and M. Anderson, "A Critical Review of Fluoride Salt Heat Transfer," Nuclear Technology, vol. 206, no. 11, pp. 1625-1641, 2020.

[29] G. Yoder, "Examination of Liquid Fluoride Salt Heat Transfer," in International Congress on Advances in Nuclear Power Plants (ICAPP), Charlotte, NC, Apr, 2014, pp. 6-9.

[30] V. Gnielinski, "New equations for heat and mass transfer in the turbulent flow in pipes and channels," NASA STI/recon technical report A, vol. 41, no. 1, pp. 8-16, 1975.

[31] U. NRC, "TRACE V5. 0 Theory Manual, field equations, solution methods, and physical models," United States Nucl. Regul. Comm, 2010. 


\section{Argonne}

Nuclear Science and Engineering Division

Argonne National Laboratory

9700 South Cass Avenue, Bldg. 208

Argonne, IL 60439

www.anl.gov 